Int. J. Dev. Biol. 51: 283-295 (2007)

doi: $10.1387 / \mathrm{ijdb} .0622391 \mathrm{~s}$

Original Article

\title{
Accumulation and dynamics of proteins of the MCM family during mouse oogenesis and the first embryonic cell cycle
}

\author{
LUKASZ SWIECH, KATARZYNA KISIEL, RENATA CZOLOWSKA, MACIEJ ZIENTARSKI and EWA BORSUK* \\ Department of Embryology, Institute of Zoology, Warsaw University, Warsaw, Poland
}

\begin{abstract}
We describe the localization of three proteins of the minichromosome maintenance (MCM) family, Mcm2, -6 and -7 in mouse ovarian oocytes. We showed that Mcm proteins are stored in two forms: soluble and insoluble. Soluble Mcm2, -6 and -7 were uniformly distributed in the nuclei of ovarian oocytes. Insoluble Mcm2 and Mcm7 (but not Mcm6) were detected in the nuclei of resting, growing and fully-grown transcribing oocytes. In transcriptionally inactive fullygrown oocytes, Mcm2 underwent redistribution and Mcm7 disappeared. A similar effect was observed when transcription in growing oocytes was inhibited with $\alpha$-amanitin. We postulate that in mouse oogenesis, the insoluble $\mathrm{Mcm}$ proteins are engaged in processes related to regulation of transcription and/or chromatin organization. In oocytes preparing for meiotic maturation, aggregates of the insoluble form of $\mathrm{Mcm} 2$ fragmented, dispersed and ultimately disappeared from the nuclei. Numerous Mcm2-positive deposits were observed in the cytoplasm of maturing oocytes. In the one-cell embryo, insoluble Mcm2 appeared in the G1 nucleus, persisted in the $S$ phase and was undetectable in the $\mathbf{G} 2$ nucleus. Such behavior of Mcm2 supports its involvement in chromatin licensing in the first embryonic cell cycle.
\end{abstract}

KEY WORDS: Mcm protein, ovarian oocyte, transcription, maturation, parthenogenetic embryo

\section{Introduction}

To maintain the integrity of their genome the proliferating cells must duplicate DNA once per cell cycle and the process must be precisely controlled at the level of the initiation and the termination of DNA synthesis. In eukaryotic cells all components required for the initiation of DNA replication are prepared in advance of the $S$ phase (i.e. during the G1 phase) and are assembled as the prereplicative complexes (pre-RCs) at the replication origins (review: Nishitani and Lygerou, 2002). Pre-RCs are built by sequential binding at the DNA origins of several initiator proteins: origin recognition complex (ORC), Cdc6/18, Cdt1 (cdc10 dependent transcript 1) and minichromosome maintenance complex (MCM) - a set of six related proteins (Mcm 2-7). This process is referred to as chromatin licensing or replication licensing (Blow and Laskey, 1988; reviews: Lei and Tye, 2001; Nishitani and Lygerou, 2002). These pre-RCs complexes are activated at the onset of $S$ phase by two protein kinases: DDK (Dbf4-dependent kinase) and CDK (cyclin dependent kinase) (review: Nishitani and Lygerou, 2002). Activation of pre-RCs allows binding to MCM of another initiator protein, Cdc45. The MCM-Cdc45 complex has DNA helicase activity and unwinds DNA duplex, making the replication origins accessible for DNA polymerases (Masuda et al., 2003). As individual replicons complete replication, the complexes of $\mathrm{Mcm}$ proteins are destabilized and released from chromatin (Todorov etal., 1995, Dimitrova et al., 1999, Dimitrova and Berezny, 2002). High CDK activity prevents formation of new pre-RCs during $S$ and $\mathrm{G} 2$ phases thus maintaining the chromatin in the unlicensed state (review: Nishitani and Lygerou, 2002). New round of chromatin licensing is possible only after the decrease in the CDK activity and the completion of mitosis (reviews: Nurse, 1997, Nishitani and Lygerou, 2002).

The Mcm2-7 proteins, the constituents of MCM complex, oscillate between two states: hyperphosphorylated (detergentsensitive, "soluble») and hypophosphorylated (detergent-resistant, «insoluble») proteins (Kimura et al., 1994; Todorov et al.,

\footnotetext{
Abbreviations used in this paper: $\mathrm{CDK}$, cyclin dependent kinase; CSK, cytoskeletal buffer; dbcAMP, dibutyryl cyclic AMP; DDK, Dbf4-dependent kinase; d pp, days post partum; GV, germinal vesicle; GVBD, germinal vesicle breakdown; $\mathrm{h}$ a.a, hours after activation; hCG, human chorionic gonadotrophin; MI, metaphase I; MII, metaphase II; MCM, minichromosome maintenance proteins; NSN, nonsurrounded nucleolus; ORC, origin recognition complex; PBS, phosphate buffered saline; $\mathrm{PBS}_{\mathrm{A}}, \mathrm{Ca} 2+, \mathrm{Mg} 2+-$ free phosphate buffered saline; PFA, paraformaldehyde; PMSG, pregnant mare's serogonadotrophin; pre-RC, pre-replication complex; $\mathrm{SN}$, surrounded nucleolus.
}

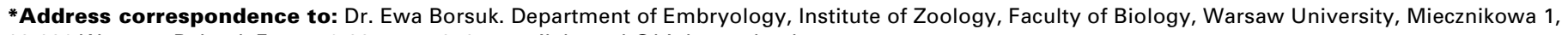
02-096 Warsaw, Poland. Fax: +48-22-55-41-210. e-mail: borsuk@biol.uw.edu.pl 
1995; Madine et al., 2000). Soluble Mcm2-7 are abundant in interphase nuclei during the whole cell cycle (Forsburg, 2004). Insoluble Mcm2-7 are typically present in G1 (licensed) and replicating (S-phase) nuclei. It is suggested that Mcm2-7 proteins bind as a heterohexamer to the region of DNA where the ORC complex binds. The insoluble (DNA-associated) Mcm2-7 are gradually detached from the chromatin while the process of DNA replication proceeds and in the G2 nuclei the insoluble form of these proteins are no longer detectable (Todorov et al., 1995; Dimitrova et al., 1999; Prasanth et al., 2004).

Nuclei of ovarian oocytes of the mouse are arrested in the diplotene of first meiotic prophase. They are thought to be in a
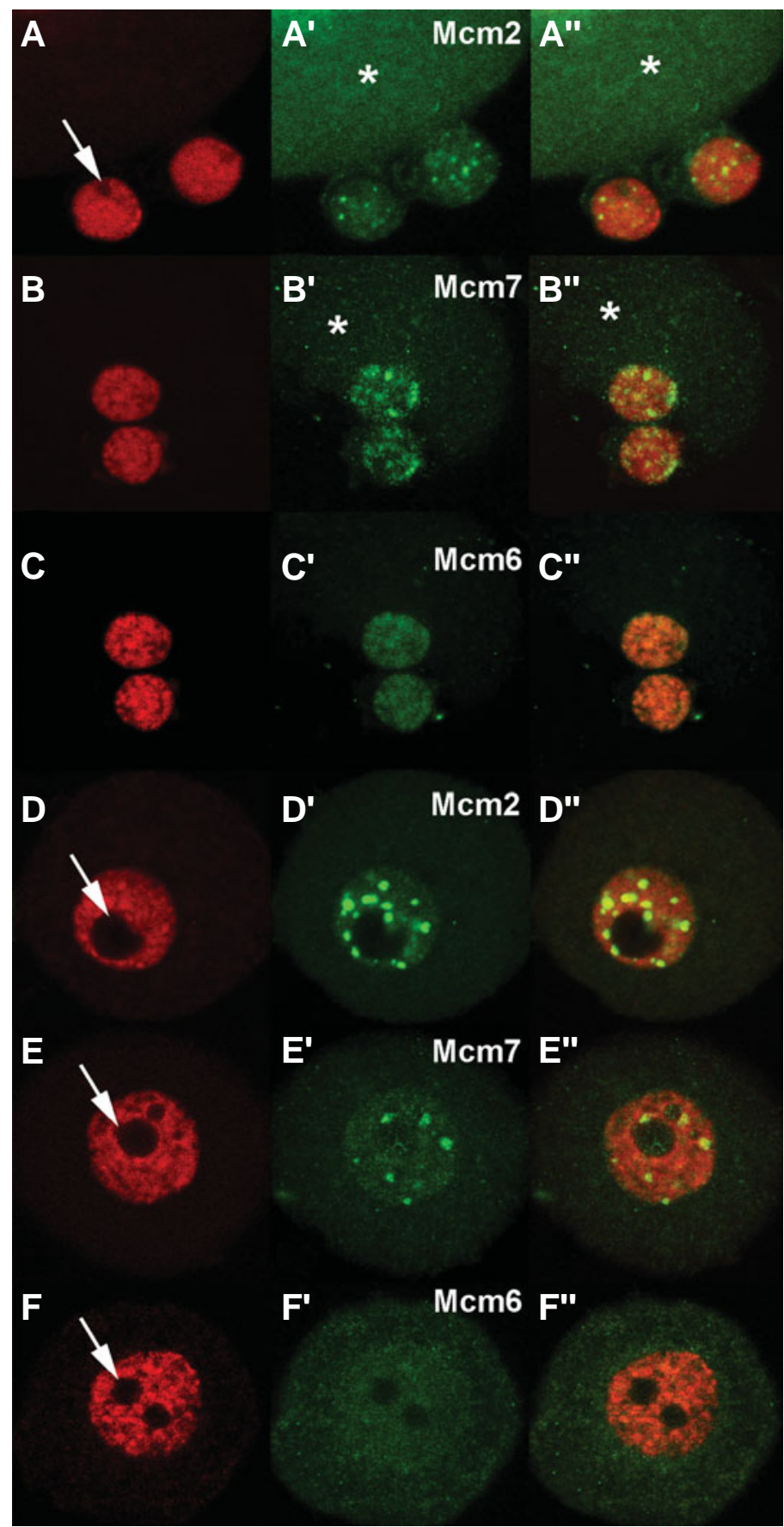

prolonged G2 phase, since the last round of DNA replication occurred in the embryonic gonad, before the entry of the germ cells into meiosis (Peters et al., 1962; Lima-de-Faria and Borum, 1962). Prolonged arrest in G2 implies that, the DNA replication must be repressed until after the completion of cell division (two meiotic divisions in mouse oocytes). Thus, the chromatin of the nucleus of mouse G2 oocyte should be in the unlicensed state and the chromatin licensing (building the pre-RC complexes) should occur with the triggering of the first embryonic cell cycle (after oocyte fertilization or artificial activation). To understand how the competence for the DNA replication is built in the activated oocyte it is necessary to know whether the proteins of pre-RC are available in oocytes. The Mcm2-7 proteins have been recently found in the fully-grown oocytes of Xenopus (Whitmire et al., 2002, Lemaître et al., 2002). The Mcm2 protein was found in the fully-grown oocytes of mouse and Drosophila (Lemaître et al., 2004) and in the primary human oocytes (Eward et al., 2004). The latter studies demonstrated the presence of total Mcm2 protein without discrimination between its two (insoluble and soluble) forms.

In the present paper we followed the distribution of Mcm2, 6 and 7 in resting, growing and fully-grown mouse ovarian oocytes as well as in maturing oocytes and parthenogenetic one-cell embryo. We show that the soluble forms of these three proteins are abundant in the nuclei of all types of ovarian oocytes studied, i.e. far in advance of the first embryonic S-phase. We document also the presence of insoluble form of Mcm2 and Mcm7, but not Mcm6 protein. Accumulation of the insoluble Mcm2 and 7 on the chromatin of ovarian oocytes may suggest their involvement in some processes occurring during oogenesis but not related to chromatin licensing. The behavior of Mcm2 during the first embryonic cell cycle was similar to the behavior of Mcm2 in cycling somatic cells, what confirms the universal role of this protein in licensing the chromatin for DNA replication.

\section{Results}

\section{Localization of insoluble forms of Mcm2, 6 and 7 in primor- dial and growing oocytes}

\section{Primordial oocytes}

The nuclei of the primordial or resting oocytes (diameter 12$14 \mu \mathrm{m}$ ) obtained from the ovaries of 2-3-days-old newborn mice, as well as the nuclei of slightly larger oocytes (diameter ca $20 \mu \mathrm{m}, 5$ days post partum $(\mathrm{d} p p)$ ) contained decondensed chromatin and stained homogenously with the chromomycin except of the area corresponding to the nucleolus, which remained unstained (Fig.1A; arrow). Insoluble Mcm2 protein

Fig. 1. Immunolocalization of insoluble Mcm2, Mcm7 and Mcm6 in the nuclei of resting and growing ovarian oocytes. Chromatin is colored in red, Mcm proteins are colored in green. Arrows indicate areas corresponding to nucleoli. Fragments of large "carrier" oocytes are indicated by asterlsks. The insoluble Mcm2 protein is visible in resting oocytes as distinct fluorescent spots (A-A") and insoluble Mcm7 forms irregular patches (B-B"). The insoluble Mcm6 protein gives uniform diffuse staining (C-C"). In growing (10-12 dpp) oocytes, the insoluble Mcm2 forms distinct fluorescent globules (D-D") and Mcm7 appears in the form of patches (EE"). The insoluble form of Mcm6 was not detected (F-F"). 


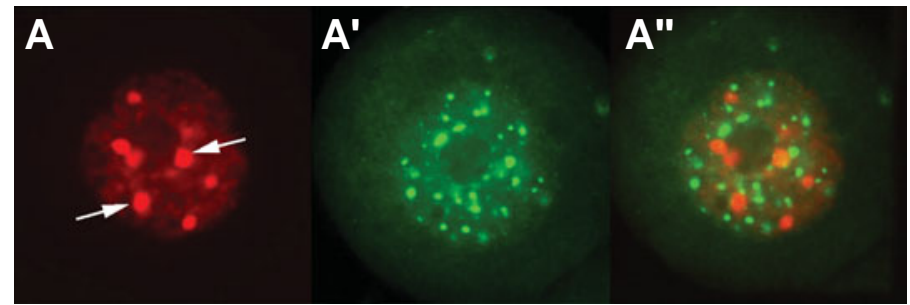

Fig. 2. Distribution of insoluble $\mathrm{Mcm} 2$ in the nuclei of growing oocytes (10 dpp). Chromatin, artificially colored in red, stained with Hoechst 33342. (A) Arrows indicate patches of highly condensed chromatin characteristic for growing oocytes. Nucleoli are visible as areas of low staining intensity. $\mathbf{M c m} 2$ protein is artificially colored in green ( $\left.\mathbf{A}^{\prime}\right)$. The globules of Mcm2 are distributed randomly in the nucleus. Merger ( $\left.\mathbf{A}^{\prime \prime}\right)$ of ( $A$ and $A^{\prime}$ ) shows that Mcm2 globules do not co-localize with the patches of highly condensed chromatin.

was visible as the distinct fluorescent spots (Fig.1 $\mathrm{A}^{\prime}$ ) and insoluble Mcm7 formed irregular patches (Fig. 1B') distributed randomly in the nucleus. In contrast to Mcm2 and 7 the immunostaining for Mcm6 protein showed only faint diffuse signal (Fig. 1C').

\section{Growing oocytes}

Mouse oocytes from the middle of growth period (from females $10-12 \mathrm{~d} p p$ ) were 50-60 $\mu \mathrm{m}$ in diameter. Their chromatin was stained with two different chromatin dyes: Hoechst dye and chromomycin (Hoechst dye binds to DNA fragments rich in AT pairs, while chromomycin binds fragments of DNA containing at least three G-C pairs). Staining with Hoechst showed that the majority of chromatin of 10-12 dpp oocytes was highly decondensed, with the exception of several dense patches (Fig. 2A; arrows) often located in the proximity of a large nucleolus. After staining with chromomycin, the chromatin was visible as a uniformly stained reticulum (Fig. 1 D,E,F; arrows indicate the nucleoli). The insoluble form of $\mathrm{Mcm} 2$ protein was visible as strongly fluorescent, randomly distributed globules, varying in number and size (Figs. 1D', 2A'). These globules did not co-localize with the dense chromatin patches visualized by Hoechst staining (Fig. 2A"). The insoluble Mcm7 protein formed several small patches less intensely stained than the Mcm2 globules, often localized in the proximity of the nucleolus (Fig. $\left.1 \mathrm{E}^{\prime}\right)$. The number of patches oscillated from 2 to 13 (5 in an average). The insoluble Mcm6 protein never formed granules or patches. Very faint, diffuse signal, slightly above the back-

Fig. 3. Distribution of insoluble $\mathbf{M c m} 2$ in fully-grown ovarian oocytes. The central (unstained) area in all nuclei corresponds to the nucleolus. (A-A") The nucleus of NSN oocyte has mostly diffuse chromatin (A) (colored in red) and centrally located nucleolus not surrounded by the chromatin rim. Mcm2 (green) forms distinct globules distributed randomly (A'). (B-B", C-C") Transitory stages between NSN and SN oocytes. Chromatin gradually condenses around the nucleolus (B,C). At the beginning of chromatin condensation, the $\mathrm{Mcm} 2$ forms large aggregates located in the proximity of the nucleolus ( $\left.\mathbf{B}^{\prime}\right)$. The size and number of aggregates changes while the process of chromatin condensation progresses (compare B' and $C^{\prime}$ ); (D-D", E-E") Two examples of SN type oocytes: chromatin forms a rim around the nucleoli, the amount of $\mathrm{Mcm} 2$ protein is reduced and it can be detected mainly outside the chromatin $\operatorname{rim}\left(\mathbf{D}^{\prime \prime}, \mathrm{E}^{\prime \prime}\right)$ ground staining of the cytoplasm was detected in the nucleoplasm (Fig. 1F')

\section{Localization of insoluble forms of Mcm2, 6 and 7 in fully- grown oocytes}

Fully-grown ovarian oocytes (diameter $>80 \mu \mathrm{m}$ ) obtained from sexually mature females belong into two main classes depending on the morphology of the nucleus: 1 . oocytes with diffuse chromatin and usually centrally located nucleolus not surrounded by the chromatin rim (NSN oocytes) and 2. oocytes with more compact chromatin and eccentrically located nucleolus surrounded by the rim of condensed chromatin (SN oocytes) (Debey et al., 1993; Zuccotti et al., 1995). A spectrum of transitory stages between NSN and SN oocytes were also found.

The insoluble form of Mcm2 protein was present in both types of fully-grown oocytes, but its distribution in the nuclei of NSN and $\mathrm{SN}$ oocytes differed significantly. NSN oocytes displayed nuclear pattern of Mcm2 distribution similar to that observed in 10-12 d $p p$ oocytes (Fig. 3A'). The distribution of insoluble Mcm2 protein in $\mathrm{SN}$ oocytes was dramatically different. In these oocytes chromatin gradually condenses beginning from the region surrounding the nucleolus (for details see Calarco et al., 1972; Debey et al., 1993; Zuccotti et al., 1995). At the early step of this process most of the chromatin forms a dense mass around the nucleolus, but

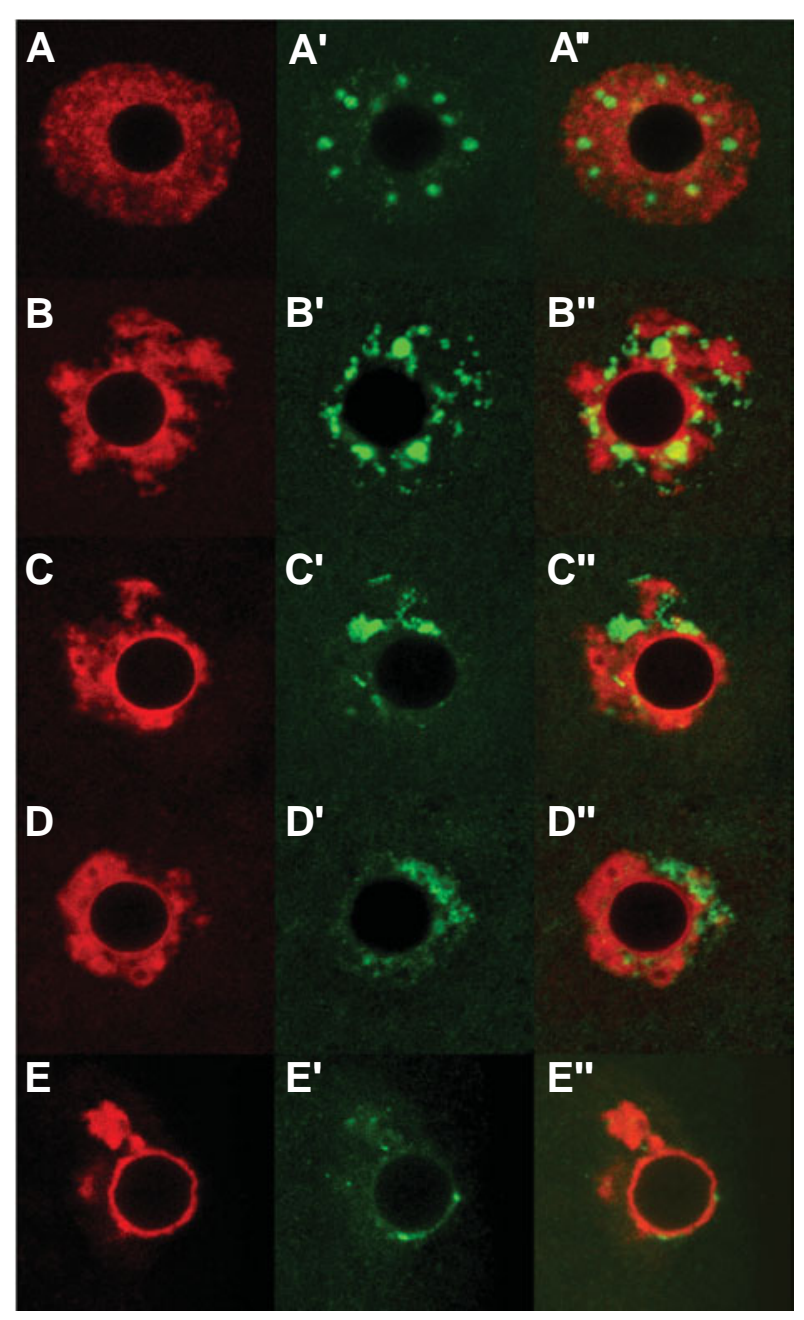


some portion of less condensed chromatin remains outside the mass (Fig. 3 B,C). The insoluble form of $\mathrm{Mcm} 2$ formed large aggregates (in the proximity of the nucleolus) and smaller spots dispersed within the nucleus (Fig. 3 B',C'). The nucleoplasm remained unstained. In a more advanced stage of chromatin condensation, the majority of the chromatin was visible as a rim around the nucleolus (Fig. 3 D,E) and the aggregates of insoluble Mcm2 protein were irregular in shape. In small, dispersed fragments of chromatin, located outside the chromatin rim the level of Mcm2 was low (Fig. 3D'). In some SN oocytes the aggregates of insoluble Mcm2 were no longer visible and the overall fluorescence of the nuclei was very faint (Fig. 3E').

The insoluble Mcm6 protein was never observed - neither in the NSN, nor in the SN oocytes (Fig. 4A'). The distribution of insoluble

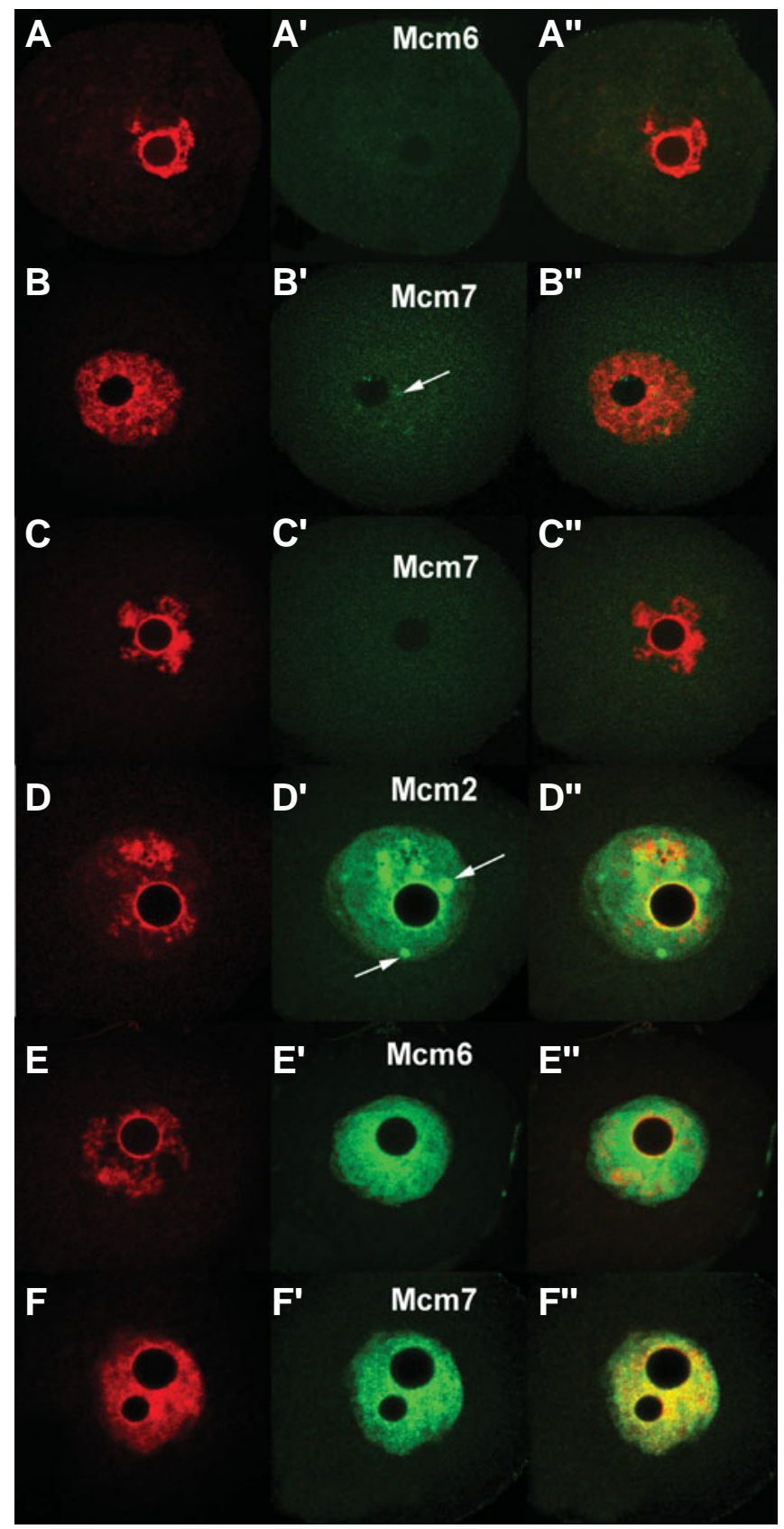

Mcm7 protein in NSN and SN oocytes differed, but these differences were less spectacular than in the case of Mcm2. In NSN oocytes Mcm7 protein formed small patches of rather low fluorescence (Fig. 4B'). In SN oocytes, the insoluble form of Mcm7 was never detected, irrespectively of the stage of chromatin condensation (Fig. 4C').

To verify whether the granules or aggregates of Mcm2 were bound to the chromatin, the fully-grown NSN and SN oocytes were treated with DNase I during the extraction procedure. After $10 \mathrm{~min}$. treatment of NSN oocytes, 3-4 single granules of insoluble form of Mcm2 protein (usually smaller and less intensively stained than in control oocytes) were observed (Supplementary material, Fig. S3 B', C'). In SN oocytes submitted to the same treatment, Mcm2 formed dispersed irregular patches (Fig. S3 D'). 30 minutes treatment with DNase I removed the remnants of the chromatin and resulted in the loss of Mcm2 staining in both types of oocytes (Fig. S3E').

\section{Localization of the total (soluble and insoluble) Mcm2, 6 and 7 proteins in primordial, growing and fully-grown oocytes}

Total (soluble and insoluble) Mcm2, 6 and 7 proteins were detected in oocytes, which were not submitted to the procedure of cell extraction. In resting and growing oocytes immunostaining with Mcm2, -6 and -7 antibodies resulted in strong, uniform fluorescence over the whole nucleus (not shown). The soluble form of Mcm2 dominated in fully-grown oocytes (both NSN and SN), masking partly the granules and patches of insoluble form (Fig. 4D'; arrows). Strong fluorescent signal, similar to observed in growing oocytes, was obtained in fully-grown oocytes immunostained with Mcm6 and Mcm7 antibody (Fig.4 E', F').

\section{Effect of $\alpha$-amanitin on chromatin configuration, transcrip- tional activity and distribution of the insoluble form of Mcm2 and $\mathrm{Mcm} 7$ proteins in growing oocytes}

We asked whether reorganization of insoluble form of $\mathrm{Mcm} 2$ and Mcm7 observed in fully-grown oocytes might be linked to changes, which are known to occur during transition from NSN to SN type of oocytes and involve chromatin remodeling and silencing of RNA synthesis (Bouniol-Baly et al., 1999; De La Fuente and Eppig, 2001). To answer this question we have analyzed the distribution of insoluble $\mathrm{Mcm} 2$ and $\mathrm{Mcm} 7$ proteins in growing oocytes, in which transcription has been inhibited by $\alpha$-amanitin.

In control growing oocytes, cultured for 20-24 h, the chromatin was dispersed and filled the entire area of the nucleus, similarly as it was observed in freshly isolated growing oocytes. In contrast, the configuration of chromatin in oocytes cultured for the same period of time in the presence of $\alpha$-amanitin was markedly changed. Chromatin condensed and often formed a dense mass surrounding the nucleolus (Fig. 5 A,D). These nuclei resembled the nuclei

Fig. 4. Distribution of insoluble and total Mcm6 and Mcm7 proteins and Mcm2 total protein in the nuclei of fully-grown ovarian oocytes. Chromatin is colored in red, while the Mcm6, Mcm7 and Mcm2 proteins are colored in green. The insoluble form of Mcm6 was never detected in fully-grown oocytes (A-A"). The remnants of insoluble Mcm7 protein (arrow) were observed in fully-grown NSN oocytes (B-B"). In SN oocytes, this form of $\mathrm{Mcm} 7$ was never detected (C-C"). The soluble form of $\mathrm{Mcm} 2$ (D-D"), Mcm6 (E-E") and Mcm7 (F-F") was detected in large quantities in NSN as well as SN oocytes. The granules of the insoluble form of Mcm2 $\left(D^{\prime}\right.$, arrows) were partly masked by diffused signal of soluble protein. 
of fully-grown SN type oocytes. The less condensed nuclei were more similar to transitory stages between NSN and SN type (Fig. 5 B,C). Control oocytes intensively synthesized RNA. In contrast, culture in the presence of $\alpha$-amanitin resulted in inhibition of transcription.

In control oocytes the distribution of insoluble form of Mcm 2 and Mcm7 was identical with that observed in freshly isolated growing oocytes (see Fig.1 D',E'). In oocytes treated with $\alpha$-amanitin the insoluble form of $\mathrm{Mcm} 2$ underwent pronounced rearrangement. The most striking was the appearance of 2 or 3 large aggregates of Mcm2 (Fig. 5 A', B'; arrows; compare with Fig. 1D'). The insoluble form of Mcm7 was also rearranged. Either $3-5$ faintly stained and highly blurred patches (resembling the patches of insoluble Mcm7 detected in fully-grown NSN oocytes) were observed (Fig. 5 C', D'), or this protein form was absent (like in SN oocytes).

\section{Localization of the insoluble form of Mcm2 during meiotic maturation}

We have shown that the only protein stored in the nuclei of fullygrown SN oocytes is the insoluble Mcm2. In some oocytes (likely preparing for meiotic maturation) this protein was partly eliminated from the nucleus (see Fig. 3E'). We focused our attention on further fates of insoluble Mcm2 in maturing oocytes. The earliest changes in the permeability of the nuclear envelope, preceding the nuclear envelope breakdown (Lénárt and Ellenberg, 2003, Lénárt et al., 2003, Kozdrój and Borsuk, unpublished data) were followed after intracytoplasmic injection of dextran conjugated with fluorescein (MW 70 000). Entrance of dextran from the cytoplasmic to the nuclear compartment marked the beginning of the maturation process. In the fully-grown SN mouse oocytes germinal vesicle breakdown (GVBD) was usually observed 10-20 min. after the penetration of dextran into the nucleus. In such oocytes insoluble Mcm2 protein never formed large aggregates. Usually smaller clusters, expressing lower fluorescent signal, were observed (Fig. 6A). Many Mcm2-positive deposits were visible in the cytoplasm, in the proximity of the GV (Fig. 6A, arrow). At the GVBD the clusters of insoluble Mcm2 were released into the cytoplasm. Initially they remained concentrated in the region occupied by the group of condensed chromatin (Fig. 6B). Within next 15 min. they underwent dispersion in the cytoplasm (Fig. 6C, arrows) and 20 min. after GVBD they were no longer visible (Fig. 6D). Cytoplasmic Mcm2positive deposits, "dots", reappeared in maturing oocytes at about $3 \mathrm{~h}$ after GVBD (Fig. 6E, arrows). Their number increased with the progression of maturation and at the metaphase of the first meiotic division (MI, 8-9 $\mathrm{h}$ after GVBD), numerous Mcm2-positive dots were dispersed randomly in the cytoplasm (Fig.6 F,G). Similar distribution was maintained during anaphase and telophase of the first meiotic division and in MII arrested oocytes (Fig. $6 \mathrm{H}-\mathrm{J}$ ). The reappearance of $\mathrm{Mcm} 2$-positive deposits in the cytoplasm of maturing oocytes occurred independently of the protein synthesis (see Supplementary material). Cytoplasmic deposits (dots) were also observed in control oocytes, maturing in vivo(see Supplementary material). In oocytes stained without the primary antibody treatment such deposits or dots were never observed.

\section{Localization of soluble and insoluble forms of Mcm2 during the first cell cycle of the parthenogenetic embryo}

To know whether Mcm2 protein appears in embryonic cells like in somatic cells, we have followed its distribution in the female

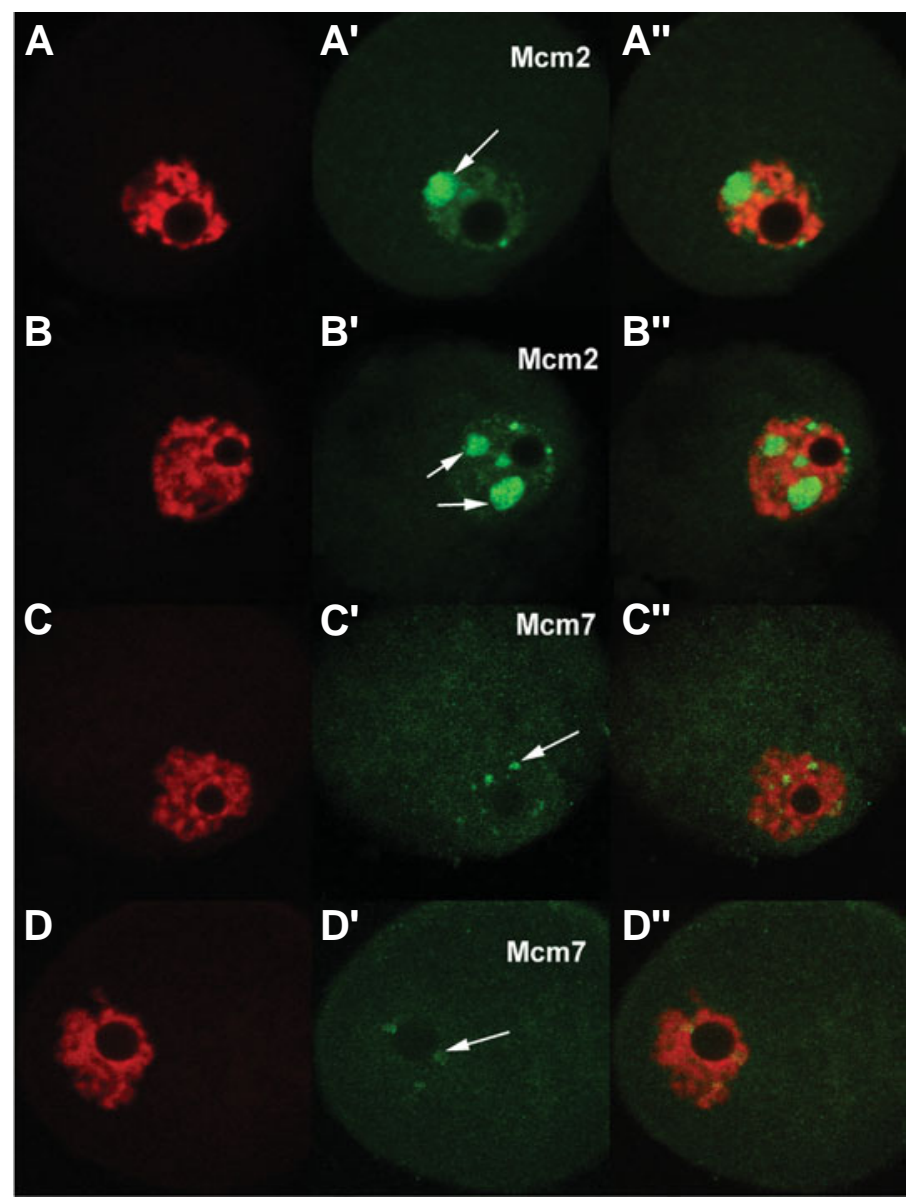

Fig. 5. Distribution of insoluble form of $\mathrm{Mcm} 2$ and $\mathrm{Mcm} 7$ in oocytes obtained from 12-days old females and cultured for $20 \mathrm{~h}$ in the presence of $\boldsymbol{\alpha}$-amanitin. Chromatin is colored in red, while the $\mathrm{Mcm} 2$ and $\mathrm{Mcm} 7$ proteins are colored in green. (A-A", B-B") Large aggregates (arrows) formed by redistribution of smaller granules of $\mathrm{Mcm} 2$ protein. (C-C", D-D") Presence and distribution of insoluble Mcm7. Together with the condensation of chromatin, the number of weakly stained patches of this protein was diminished (compare $C^{\prime}$ and $D^{\prime}$ ).

pronucleus of one-cell parthenogenetic embryo. Artificial activation of ovulated mouse oocytes triggers resumption of meiosis (i.e. completion of the second meiotic division). After extrusion of the second polar body, activated eggs enter the first embryonic cell cycle with typical G1, S, G2 and M phases. In our experiment (see Materials and Methods) oocytes activated artificially formed haploid nucleus (female pronucleus) about $31 / 2$ - $4 \mathrm{~h}$ after activation (a.a.), entered S phase about 5-6 h a.a. and completed replication at $13 \mathrm{~h}$ a.a. First embryonic mitoses usually occurred between 16 and $18 \mathrm{~h}$ a.a. in a given group of parthenogenetic embryos.

To detect the total (soluble and insoluble) Mcm2 protein the immunostaining with anti-Mcm2 antibody was performed on onecell embryos not submitted to extraction procedure. The soluble form of Mcm2 was abundant in the pronuclei of one-cell embryos and masked the presence of the insoluble Mcm2. Strong, uniform fluorescence was observed over the pronuclei independently of the phase of cell cycle (compare: pronuclei in G1 (Fig. 7A') and in G2 (Fig. 8A')). Mcm2-positive dots, similar to observed in maturing oocytes and probably representing the insoluble form of Mcm2 


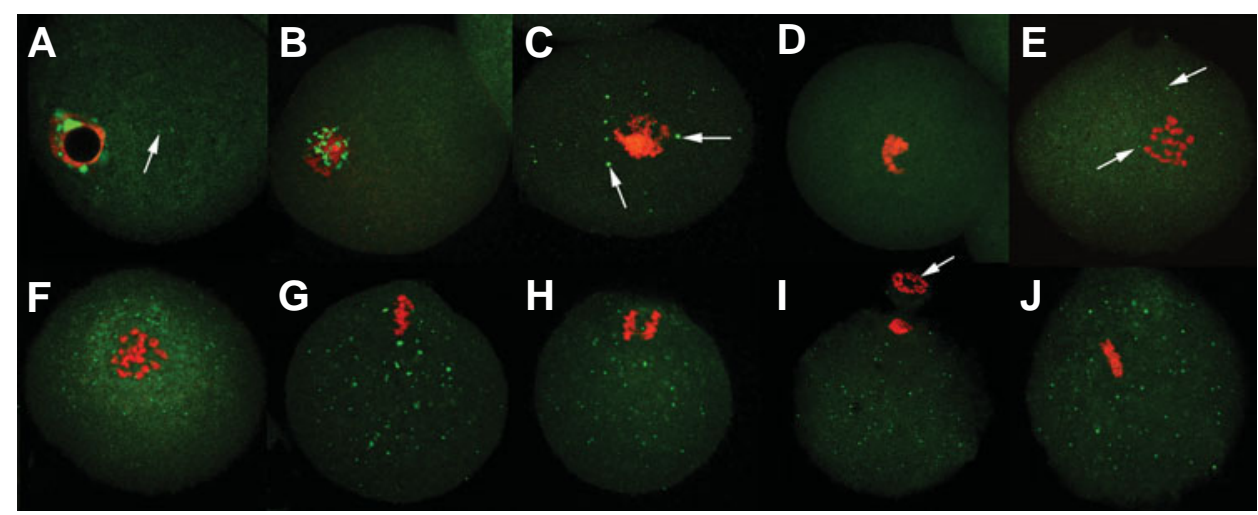

Fig. 6. Distribution of insoluble form of Mcm2 in oocytes maturing in vitro. Chromatin is colored in red; the $\mathrm{Mcm} 2$ protein is colored in green. (A) Oocyte treated with extraction buffer and fixed $15 \mathrm{~min}$. after the penetration of dextran into the germinal vesicle (GV). In the nucleus, Mcm2 still forms aggregates, although smaller than in GV-intact oocytes; Mcm2-positive dots visible in the cytoplasm (arrow). (B) Oocyte at GV breakdown (GVBD). The remnants of Mcm2 remain in the proximity of condensed mass of chromatin. (C) 10 min. after GVBD. Mcm2 (arrows) undergoes dispersion in the cytoplasm. (D) $20 \mathrm{~min}$. after GVBD. The

insoluble form of Mcm2 is not present. (E) 3 h after GVBD. Mcm2-positive dots reappear in the cytoplasm (arrows). (F) 6 h after GVBD (prometaphase I). Mcm2-positive dots concentrate around the metaphase plate. (G-I) 8-9 h after GVBD. (G) Metaphase I. Mcm2-positive deposits scattered randomly in the cytoplasm; this distribution is maintained in anaphase / (H) and telophase I (I) (arrow indicates chromatin of the $1^{\text {st }}$ polar body). (J) $10-12 \mathrm{~h}$ after GVBD, metaphase II. Mcm2-positive dots still present in the cytoplasm.

protein, were present in the cytoplasm of non-extracted onecell embryos at G1 (Fig. 7A', arrow). The overall, diffused fluorescent signal in the cytoplasm was slightly higher in embryos at $\mathrm{G} 2$ and such dots of insoluble, cytoplasmic Mcm2 were not visible (Fig. 8A').

The pattern of the distribution of insoluble form of $\mathrm{Mcm} 2$ in the pronuclei varied depending on the phase of the cell cycle. In $\mathrm{G} 1$ and S pronuclei ( $\mathrm{h}$ a.a. and $7 \mathrm{~h}$ a.a., respectively) the spots of insoluble Mcm2 protein were distributed within the whole nucleus (Fig. 7 B', C'). In contrast, in G2 female pro-

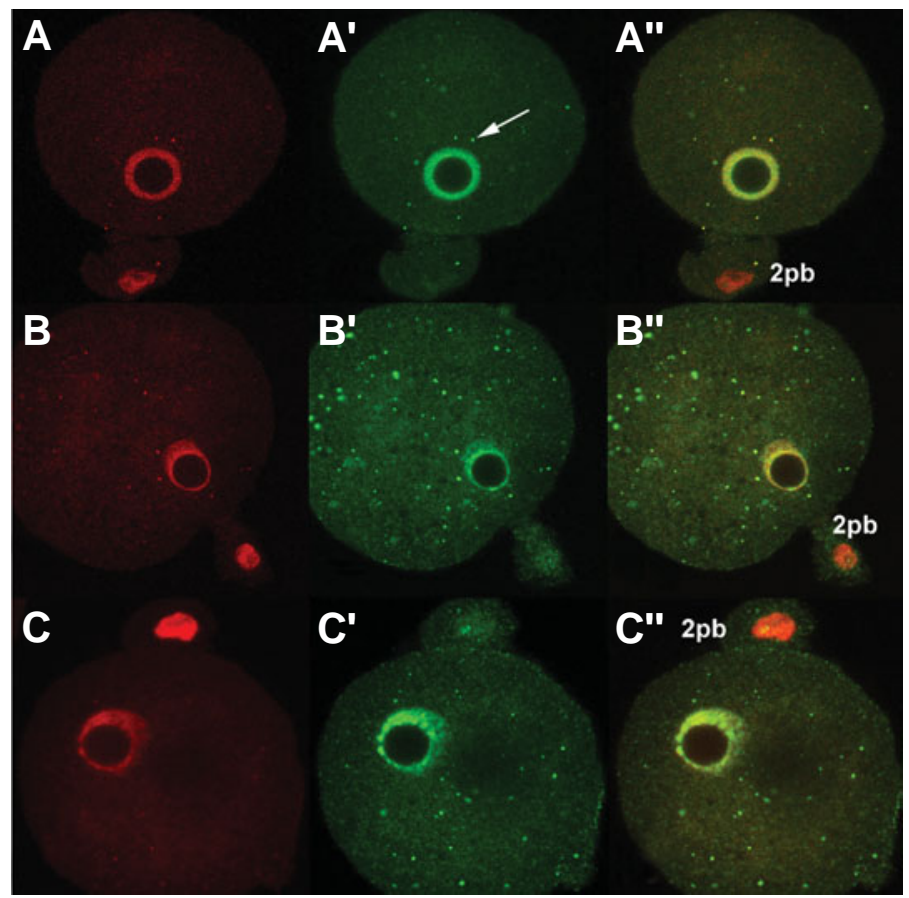

Fig. 7. Distribution of soluble and insoluble forms of Mcm2 protein in $\mathbf{G 1}$ and $\mathbf{S}$ phases of parthenogenetic one-cell embryos. Chromatin is colored in red, while the Mcm2 protein is colored in green. Unstained area in the pronucleus corresponds to the nucleolus-like body. Numerous Mcm2-positive deposits visible in the cytoplasm; see arrow in ( $\left.\mathbf{A}^{\prime}\right)$ and also $\left(\mathbf{B}^{\prime}, \mathbf{C}^{\prime}\right)$. Insoluble $\mathrm{Mcm} 2$ is detected as a spotted fluorescence in the pronucleus. nucleus the insoluble form of $\mathrm{Mcm} 2$ protein almost disappeared (Fig. 8 B-B"; signal of replication only in the $2^{\text {nd }}$ polar body).

The cytoplasmic dots, probably representing the insoluble, cytoplasmic form of $\mathrm{Mcm} 2$, were found also in one-cell embryos submitted to extraction procedure. Their number, size and intensity of staining diminished during the progression of the cell cycle. The largest and most numerous dots were observed in G1 embryo (Fig. 7B'), in S phase they were smaller and less numerous (Fig. 7C') and finally, in G2 embryo they were scarce (Fig. 8B').

\section{Discussion}

In the present work we demonstrated the presence and the localization of three proteins of MCM family, Mcm2, 6 and 7 in the mouse ovarian oocytes. We showed that two of them, Mcm2 and $\mathrm{Mcm} 7$, appeared in two forms: the insoluble (detergentresistant) and soluble (detergent-sensitive) while the Mcm6 was detected only in the soluble form. The soluble Mcm proteins were uniformly distributed in the nuclei of resting oocytes, obtained from 2-3 days old females, as well as in the nuclei of growing and fully-grown oocytes. Insoluble Mcm2 and Mcm7 proteins, organized into granules or patches, were present in the nuclei of resting, growing and fully-grown NSN oocytes. The distribution of insoluble $\mathrm{Mcm} 2$ and $\mathrm{Mcm} 7$ proteins changed during the oocyte growth with the most dramatic changes occurring in the nuclei of fully-grown oocytes during the transition from the NSN to $\mathrm{SN}$ type of chromatin configuration. Tracing further behavior of insoluble Mcm2 we have shown also that this protein was gradually eliminated from the germinal vesicle of $\mathrm{SN}$ oocytes preparing for maturation and reappeared $3 \mathrm{~h}$ after GVBD in the form of cytoplasmic deposits (dots) that were next detected until the end of meiotic maturation and persisted in parthenogenetic one-cell embryo. In the first embryonic cell cycle, the insoluble $\mathrm{Mcm} 2$ protein was detected in G1 and was still present in S-phase pronuclei. In G2 embryos the insoluble form of $\mathrm{Mcm} 2$ disappeared from the pronuclei, while soluble Mcm2 was present in the pronuclei during the whole cell cycle. Such protein behavior was described previously for Mcm2 (Todorov et al., 1995; Dimitrova et al., 1999, Prasanth et al., 2004) and other proteins of MCM family, such 
as Mcm3 (Dimitrova et al., 2002, Prasanth et al., 2004) and Mcm7 (Dimitrova and Berezney, 2002), in proliferating mammalian somatic cells.

Progression of the first cell cycle of the mouse embryo and particularly the entering of the $S$ phase, require that all factors necessary for chromatin licensing should be synthesized and stored in the oocyte during oogenesis. On the other hand, mouse ovarian oocyte, remains for weeks or months arrested in the prophase of the first meiotic division and thus requires an efficient mechanism that prevents DNA replication. This is probably why the ovarian oocytes lack of certain components of pre-RC complexes such as the Cdc6 protein, which is involved in the loading of the MCM proteins on to chromatin. Cdc6 protein is absent in the nuclei of fully-grown oocytes of Drosophila, Xenopus and mouse and is not synthesized before the initiation of maturation (Lemaître et al., 2002; 2004; Whitmire et al., 2002, Anger et al., 2005). In contrast, another component of pre-RC complex, the Mcm2 protein, was shown to be stored in the nuclei of fully-grown mouse oocytes (Lemaître et al., 2004). The method applied by these authors allowed the visualization of total Mcm2 protein (without discrimination between soluble and insoluble form). In the present study we showed that not only the Mcm2, but also Mcm6 and 7 are present during mouse oogenesis and that $\mathrm{Mcm} 2$ and $\mathrm{Mcm} 7$ are accumulated in the oocyte also in the insoluble form. The role of these insoluble proteins is intriguing. The oocyte chromatin is in the unlicensed state, as is the chromatin of G2 somatic cell. Logically the insoluble proteins of the MCM family (generally engaged in DNA replication) should be absent. However, there are reports demonstrating that MCMs may have additional functions including chromatin remodeling, response to DNA damage and regulation of transcription (reviews: Bailis and Forsburg, 2004; Forsburg, 2004). MCM proteins were shown to be the components of polymerase II transcriptional complexes that were isolated as high-molecular-weight holoenzyme units from $\mathrm{Xe}$ nopus oocytes and HeLa cells (Yankulov et al., 1999). Antibodies to Mcm2 inhibited transcription in Xenopusoocytes (Yankulov et al., 1999). The insoluble form of Mcm2 and/or Mcm7 existing in mouse oocytes might therefore be a component of large enzyme machinery engaged in transcription.

RNA synthesis in the mouse oocytes is initiated soon after the birth of the female, continues during the entire period of oocyte growth and proceeds in the fully-grown NSN oocytes (review: Bachvarova, 1985; Bouniol-Baly et al., 1999). Silencing of transcriptional activity appears concomitantly with the condensation of chromatin and its accumulation around the nucleolus during the transition to SN type oocyte (Bouniol-Baly et al., 1999), two events that are probably controlled by different mechanisms (Burns et al., 2003, De La Fuente et al., 2004). During this transition, the Mcm2- and Mcm7-positive structures were reorganized and finally removed from the nucleus. Moreover, we have found that inhibition of RNA synthesis in oocytes obtained from 12-days old females, resulted in the condensation of chromatin and reorganization of insoluble form of $\mathrm{Mcm} 2$ and Mcm7. Formation of large aggregates, occurring concomitantly with transcriptional silencing and condensation of chromatin (either physiological in fully-grown SN oocytes, or induced by $\alpha$-amanitin treatment of oocytes obtained from 12days old mouse females), was previously observed in the case of splicing factor SC-35 (Borsuk et al., 1996). We can not exclude that such rearrangement of $\mathrm{Mcm}$-positive structures occurs via a passive movement with condensing chromatin, having no relation to silencing of the transcription.

The DNA digestion with DNase I revealed that granules or aggregates of insoluble Mcm2 observed in fully-grown oocytes were associated with the chromatin. In somatic cells this protein is bound to the chromatin only when the other proteins of the pre-RC complex are already present in there. It has been proved that $\mathrm{Cdc} 6$ protein plays a crucial role in this process (Madine et al.,2000; Lei and Tye, 2001; Sun et al., 2000). For the moment it is difficult to say how is the Mcm2 protein bound to the chromatin in fully-grown mouse oocytes, specially in the light of results presented by Lemaître et al. (2004), who have shown that Cdc6 protein is absent in the germinal vesicle of fully-grown mouse oocytes.

In SN oocytes preparing for maturation, Mcm2 and Mcm7 proteins shifted from the insoluble (hypophosphorylated) to soluble (hyperphosphorylated) form and the soluble proteins dominated in the nucleus. These changes correlate well with phosphorylation changes in oocytes initiating maturation (Choi et al., 1991). Prevalence of soluble MCMs is typical for G2 nucleus of somatic cell (Todorov et al., 1995; Dimitrova et al., 1999; Prasanth et al., 2004) and for G2 pronucleus of one-cell parthenogenetic mouse embryo (this work). In the case of mouse oocytes, only the most advanced stage of ovarian oocytes gain the feature typical for G2.

In the present studies we also showed the presence of Mcm2-positive deposits (dots) in the cytoplasm. They appeared for the first time in oocytes maturing in vitro, just before and soon after GVBD. Then they disappeared and reappeared at prometaphase I independently of the protein synthesis de novo. Again, changes in the phosphorylation may play a role in these modifications. The Mcm2-positive dots were also observed in the cytoplasm of oocytes maturing in vivo as well as

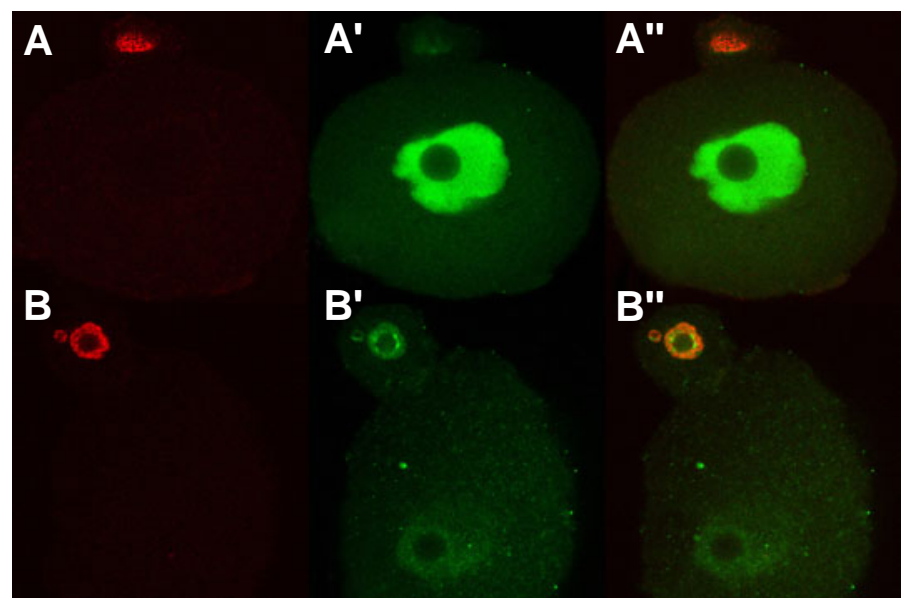

Fig. 8. DNA replication and distribution of soluble and insoluble Mcm2 protein in $\mathbf{G} 2$ phase of parthenogenetic one-cell embryos. DNA replication is colored in red, while $\mathrm{Mcm} 2$ protein is colored in green. In late G2 (18 hours after activation), only the nucleus of the $2^{\text {nd }}$ polar body continues replication; see red in $(\mathbf{A}, \mathbf{B})$. Soluble $\mathrm{Mcm} 2$ fills uniformly the pronucleus $\left(\mathbf{A}^{\prime}\right)$. Insoluble $\mathbf{M c m} 2$ is present in the $2^{\text {nd }}$ polar body nucleus, but is almost absent in the pronucleus (B'). 
during the first cell cycle of parthenogenetic embryo. Their distribution was in most cases random except the oocytes at prometaphase I where dots seemed to concentrate in the region around the metaphase plate. This observation contradicts the data presented by Lemaître et al. (2004) who have shown that in mouse metaphase II oocytes Mcm2 is localized exclusively in the region around the metaphase spindle. This discrepancy may be explained by different procedures used in two approaches. Lemaître and colleagues used Drosophila anti-Mcm2 primary antibody and presented the total (soluble and insoluble) protein in oocytes not submitted to the extraction procedure. In our approach Mcm2 protein has been detected in extracted oocytes by the goat anti-Mcm2 primary antibody which specificity has been confirmed on Western blots and by immunodetection of Mcm2 in somatic cells (Suppl. material, Figs. S1 and S2).

During the first cell cycle of parthenogenetic embryo the cytoplasmic deposits of Mcm2 were most numerous at G1 and almost disappeared at G2, at the time when the insoluble form of nuclear Mcm2 shifted to soluble one. Whether Mcm2-positive dots constitute the cytoplasmic store of replication-related protein remains to be established. Such cytoplasmic deposits of proteins of MCM family have never been described in somatic cells, although the necessity of the formation of cytoplasmic aggregates of the MCM proteins in Saccharomyces pombe was suggested by Pasion and Forsburg (1999). It is worthy to recall that multiple cytoplasmic deposits of Cdc6 protein were detected in immunostained HeLa and $\mathrm{CHO}$ cells (Alexandrow et al., 2004).

Although, at present, no particular function can be attributed to accumulation of Mcm proteins in the nuclei of mouse ovarian oocytes and to Mcm2 deposits in the cytoplasm, we hope that our observations open a new path for further exploration of the subject.

\section{Materials and Methods}

Ethical approval for presented study was obtained from the Local Ethic Committee No.1 in Warsaw (Poland). Oocytes were obtained from $\mathrm{F} 1(\mathrm{C} 57 \mathrm{BL} / 10 \times \mathrm{CBA} / \mathrm{H})$ and $\mathrm{F} 1(\mathrm{C} 57 \mathrm{BL} / 6 \times \mathrm{CBA} / \mathrm{H})$ females and from $F 1$ females of reverse crosses. The chemicals were purchased from Sigma-Aldrich Co. (Germany) unless stated otherwise.

\section{Collection of the oocytes}

\section{Early oocytes}

Non-growing oocytes (primordial or resting, diameter 12-14 $\mu \mathrm{m}$ ) were obtained from 2-3-days-old newborns. Oocytes just initiating growth (diameter ca $20 \mu \mathrm{m}$ ) were recovered from 5-days-old females. The ovaries were freed of adhering tissues in M2 medium (Fulton and Whittingham, 1978) and incubated for $15 \mathrm{~min}$ at $37^{\circ} \mathrm{C}$ in phosphate buffered saline (PBS, Biomed, Poland) containing testicular hyaluronidase (type I-S), collagenase (type I) and egg white lysozyme (International Enzymes, UK) $(0.5 \mathrm{mg} / \mathrm{ml}$ of each) according to the method of Mangia and Epstein (1975). Isolated oocytes were cultured in $\mathrm{M} 2$ medium, under paraffin oil, at $37^{\circ} \mathrm{C}$, in $5 \% \mathrm{CO}_{2}$ in the air. To make further manipulations of early oocytes easier, they were aggregated with fully-grown "carrier" oocytes. After few minutes of preincubation in phytohemagglutinin ( $300 \mu \mathrm{g} / \mathrm{ml}$ in BSA-free M2 medium) in an agarcoated watch glass, several early oocytes were aggregated with a single carrier oocyte. The aggregates were washed in M2 medium and then processed for cell extraction and/or fixation for immunostaining (see below).

\section{Growing oocytes}

A population of growing oocytes (diameter 50-60 $\mu \mathrm{m}$ ) was obtained by puncturing the ovaries of sexually immature females (10 - 12 days postpartum) in M2 medium. The zonae pellucidae were removed with $0.5 \%$ Pronase in Ringer's solution. Zona-free growing oocytes were processed for cell extraction and/or fixation for immunostainig.

\section{Fully-grown oocytes}

Adult females were injected intraperitoneally with pregnant mare's serogonadotrophin (PMSG, $10 \mathrm{IU}$; Intervet International B.V., Boxmeer, Holland) to stimulate the growth of the follicles and $49-52 \mathrm{~h}$ later they were sacrificed by cervical dislocation. Oocytes were obtained by puncturing the largest follicles of excised ovaries in M2 medium supplemented with dibutyryl cyclic AMP (dbcAMP, $150 \mu \mathrm{g} / \mathrm{ml}$ ) to prevent spontaneous maturation. Zonae pellucidae were removed with $0.5 \%$ Pronase in Ringer's solution. Zona-free oocytes were washed in M2+dbcAMP, incubated for 30 minutes in the same medium and processed for cell extraction and/or fixation for immunostaining.

\section{Meiotic maturation of fully-grown oocytes}

Fully-grown oocytes were obtained from adult females in M2+dbcAMP as it was described above. They were classified into NSN and SN oocytes under vital conditions according to the method described by Debey et al. (1989). Briefly, oocytes were incubated for $30 \mathrm{~min}$. in M2+dbcAMP supplemented with $2 \mathrm{ng} / \mathrm{ml}$ of Hoechst dye (bisbenzimid H 33342, Riedelde-Häen, Netherlands). Afterwards their chromatin configuration was analyzed with the help of fluorescent microscope (Axiovert 135, Carl Zeiss Jena, Jena, Germany). The UV radiation was reduced to nonharmful level using the neutral attenuation filter ( $x 0.03$, Carl Zeiss Jena). Images were recorded with the CCD camera (Pixelfly, PCO, Germany). Only oocytes classified as SN type were used for in vitro maturation. To indicate precisely the moment of germinal vesicle breakdown (GVBD) the oocytes were microinjected with dextran conjugated with FITC (MW 70 000, Molecular Probes, Eugene, USA) using the method of Lénárt et al. (2003). Intracytoplasmic microinjections were performed with the help of Eppendorf microinjector (type 5242, Eppendorf, Germany) connected with micromanipulator Leitz (Leitz, Germany). The solution of dextran was prepared immediately before microinjection from the stock solution ( $10 \mathrm{mg} / \mathrm{ml}$ of distilled water) diluted to final concentration of $2 \mathrm{mg} / \mathrm{ml}$ in 2 $\mathrm{mM}$ Pipes buffer ( $\mathrm{pH} 7.4$ ) containing $0.14 \mathrm{M} \mathrm{KCl}$. Afterwards oocytes were washed in M2 medium to remove dbcAMP and cultured in vitro in this medium. They were observed under fluorescent microscope until initiation of nuclear envelope breakdown signalized by entrance of dextran into germinal vesicle (Lénárt et al., 2003). Some of these oocytes were immediately submitted to extraction procedure. The other were cultured in vitro and subjected to cell extraction at the moment of GVBD, 15-20 min. after GVBD and 1, 3, 5, 6, 8-9, 10-11 and $12 \mathrm{~h}$ after GVBD. Their zonae pellucidae were removed with acidic Tyrode's solution $(\mathrm{pH} 2.5) 30$ min. before extraction. Oocytes maturing in vivoserved as a control group (see Supplementary Material at the end of this article).

\section{Parthenogenetic one-cell eggs}

Ovulated (metaphase II-arrested) oocytes were obtained from adult female mice, induced to ovulate with PMSG and human chorionic gonadotrophin (hCG, $10 \mathrm{IU}$; Intervet International B.V., Boxmeer, Holland). Chorionic gonadotrophin was administered 48 to $54 \mathrm{~h}$ after injection of PMSG. Oocytes were harvested $17 \frac{1}{2}-18 \mathrm{~h}$ after $\mathrm{hCG}$ injection, treated with hyaluronidase $\left(500 \mu \mathrm{g} / \mathrm{ml}\right.$ in $\mathrm{Ca}^{2+} / \mathrm{Mg}^{2+}$-free PBS) to remove cumulus cells and washed in M2 medium. They were activated parthenogenetically $18-18 \frac{1}{2}$ h after hCG injection, by exposure to $8 \%$ ethanol in M2 for 8 min (Cuthbertson et al., 1981; Cuthbertson, 1983). Activated eggs (judged by the presence of the $2^{\text {nd }}$ polar body and female pronucleus), 
were cultured in M2 medium until they have reached the desired phase of the first cell cycle. Some eggs were injected into the cytoplasm with digoxigenin-11-dUTP (dig-11-dUTP; $1 \mathrm{mM}$ solution-undiluted commercial product, Roche Diagnostics $\mathrm{GmbH}$, Germany), using an Eppendorf microinjector. Microinjections were performed 4,7 and $16 \mathrm{~h}$ after activation. Injected eggs were cultured in M2 for 30 to 60 minutes. After removing zonae pellucidae, injected and non-injected eggs were submitted to cell extraction and/or fixation for immunostaining.

\section{Inhibition of transcription in growing oocytes by $\alpha$-amanitin treat- ment}

Growing oocytes obtained from females at 10-12 days postpartum were placed in drops of Dulbecco's modified Eagle's medium (DMEM; Invitrogen, Eugene, USA) supplemented with $10 \% \mathrm{FBS}$, antibiotics and with $4.5 \mathrm{mg} / \mathrm{ml}$ of glucose, containing $\alpha$-amanitin $(10 \mu \mathrm{g} / \mathrm{ml})$ and cultured under standard conditions. Control group of oocytes was cultured for the same period of time in DMEM medium without $\alpha$-amanitin. After $20 \mathrm{~h}$ of culture the zonae pellucidae of oocytes from both groups were removed with Pronase. Zona-free oocytes were then incubated for 30 minutes in medium with or without $\alpha$-amanitin and processed for cell extraction and fixation for immunostaining.

\section{Detection of transcription}

Transcription in growing oocytes cultured in the presence of $\alpha$ amanitin and in control oocytes was examined according to the method of Bouniol et al. (1995). After $19 \mathrm{~h}$ of culture oocytes were microinjected with 1-2 pl of BrUTP (100 mM solution in $2 \mathrm{mM}$ Pipes buffer with $140 \mathrm{mM}$ $\mathrm{KCl}, \mathrm{pH} 7.4$ ), cultured for the next 30 minutes and fixed for immunocytochemistry. BrU incorporation was detected using mouse monoclonal anti-BrdU antibody $(\lg G)$ as the primary antibody and FITC-conjugated goat anti-mouse IgG $(\mathrm{H}+\mathrm{L}$ ) secondary antibody (Caltag Laboratories, Burlingame, CA, USA). To visualize the chromatin the oocytes were stained with chromomycin A3 $(10 \mu \mathrm{g} / \mathrm{ml}$ PBS).

\section{Cell extraction and fixation}

To visualize insoluble form of Mcm2, 6 and 7 proteins, the oocytes were extracted using the method of Sun et al. (2000). After washing with ice-cold $\mathrm{Ca}^{+2} / \mathrm{Mg}^{+2}$-free PBS $\left(\mathrm{PBS}_{\mathrm{A}}\right.$ ) and ice-cold cytoskeleton (CSK) buffer (10 mM Pipes, pH 7.0, $100 \mathrm{mM} \mathrm{NaCl}, 300 \mathrm{mM}$ sucrose, $3 \mathrm{mM}$ $\mathrm{MgCl}_{2}$ ) oocytes were treated with CSK buffer containing $0.5 \%$ Triton X$100,0.5 \mathrm{mM}$ PMSF, $10 \mu \mathrm{g} / \mathrm{ml}$ of both leupeptin and aprotinin, for $3 \mathrm{~min}$ on ice. In some of the fully-grown oocytes DNA was digested with DNase I. For this purpose DNase I $(100 \mu \mathrm{g} / \mathrm{ml})$ has been added to the extraction buffer and the oocytes were treated with this buffer for $10-30$ min. at $37^{\circ} \mathrm{C}$. Control oocytes were submitted to the same procedure in DNase I free extraction buffer. Immediately after extraction oocytes were fixed in $2 \%$ paraformaldehyde (PFA) in $\mathrm{PBS}_{A}$ for 20 min and blocked for at least 60 min in $2 \%$ BSA (bovine serum albumin, fraction $V$ ) in $\mathrm{PBS}_{\mathrm{A}}$ before immunostaining.

To demonstrate the total (soluble and insoluble) Mcm2, 6 and 7 proteins, the oocytes not submitted to cell extraction were fixed in $2 \%$ PFA for 20 min and after washing in $\mathrm{PBS}_{A}$ they were permeabilized in $0.2 \%$ Triton X-100 in PBS $_{A}$ and blocked for at least 60 min in $2 \% B_{S A}$ in PBS $_{A}$ before immunostaining.

\section{Immunostaining}

The Mcm2 and 6 proteins were detected using, respectively, goat polyclonal anti-Mcm2 (N-19, sc-9839) and anti-Mcm6 (C-20, sc-9843) primary antibodies (Santa Cruz Biotechnology Inc., USA) and FITCconjugated donkey anti-goat $\lg G(\mathrm{H}+\mathrm{L})$ secondary antibody (Jackson Immunoresearch Laboratories, Inc., USA). The Mcm7 protein was detected using mouse monoclonal anti-Mcm7 primary antibody (sc-9966, Santa Cruz Biotechnology Inc., USA) and TRITC-conjugated goat antimouse $\lg G+\lg M(H+L)$ secondary antibody (Jackson Immunoresearch Laboratories, Inc., USA). To visualize the chromatin, oocytes were stained with Hoechst 33342 (bisbenzimid $\mathrm{H} 33342$, 2-4 $\mu \mathrm{g} / \mathrm{ml} \mathrm{PBS}_{A}$, Riedel-de-Häen, Netherlands) or chromomycin A3 $(10 \mu \mathrm{g} / \mathrm{ml}$ PBS $)$. Specificity of the immunoreaction was checked on oocytes stained without the incubation with primary antibody.

\section{Microscopy}

Oocytes were mounted on poly-L-lysine-coated $\left(10 \%\right.$ solution in $\left.\mathrm{H}_{2} \mathrm{O}\right)$ slides in the mounting medium - Citifluor (glycerol/PBS solution; Citifluor Ltd., London, U.K.). In some cases Vectashield with propidium iodide (Vector Laboratories, Inc., USA), was used instead of Citifluor. Preparations were analyzed using a confocal microscope (LSM 510, Carl Zeiss Jena, Germany) or an epifluorescence microscope (Axiovert 135; Carl Zeiss Jena, Germany), equipped with CCD camera (Pixelfly, PCO, Germany).

\section{Control of the specificity of primary antibodies}

The specificity of the primary antibodies was confirmed on the Western blots on protein lysats prepared from the ovaries obtained from sexually immature (13 days old) and sexually mature (2 months old) females and from ovulated oocytes (Supplementary material; Fig. S1). Additionally the same primary antibodies have been used for immunodetection of $\mathrm{Mcm} 2$, 6 and 7 in somatic cells (Supplementary material; Fig. S2).

\section{Acknowledgements}

This work was partly financed by a grant from the State Committee for Scientific Research (grant 3P04C 001 25). Authors thank Prof. A.K. Tarkowski and Prof. M. Maleszewski for critical reading of the manuscript and Dr. E. Brzóska-Wójtowicz for preparing the culture of C2C12 cells.

\section{References}

ALEXANDROW, M.G. and HAMLIN, J.L. (2004). Cdc6 chromatin affinity is unaffected by serine-54 phosphorylation, S-phase progression and overexpression of cyclin A. Mol Cell Biol24: 1614-27.

ANGER, M., STEIN, P. and SCHULTZ, R.M. (2005). CDC6 requirement for spindle formation during maturation of mouse oocytes. Biol Reprod72: 188-94.

BACHVAROVA, R. (1985). Gene expression during oogenesis and oocyte development in mammals. Dev Bio/(N.Y. 1985) 1: 453-524.

BAILIS, J.M. and FORSBURG, S.L. (2004). MCM proteins: DNA damage, mutagenesis and repair. Curr Opin Genet Dev 14: 17-21.

BLOW, J.J. and LASKEY, R.A. (1988). A role for the nuclear envelope in controlling DNA replication within the cell cycle. Nature 332: 546-8.

BORSUK, E., VAUTIER, D., SZÖLLÖSI, M.S., BESOMBES, D. and DEBEY, P (1996). Development-dependent localization of nuclear antigens in growing mouse oocytes. Mol Reprod Dev 43: 376-86

BOUNIOL-BALY, C., HAMRAOUI, L., GUIBERT, J., BEAUJEAN, N., SZÖLLÖSI M.S. and DEBEY, P. (1999). Differential transcriptional activity associated with chromatin configuration in fully grown mouse germinal vesicle oocytes. Biol Reprod60: 580-7.

BOUNIOL, C., NGUYEN, E. and DEBEY, P. (1995). Endogenous transcription occurs at the 1-cell stage in the mouse embryo. Exp Cell Res 218: 57-62.

BURNS, K.H., VIVEIROS, M.M., REN, Y., WANG, P., DEMAYO, F.J., FRAIL, D.E., EPPIG, J.J. and MATZUK, M.M. (2003). Roles of NPM2 in chromatin and nucleolar organization in oocytes and embryos. Science 300: 633-6.

CALARCO, P.G., DONAHUE, R.P. and SZÖLLÖSI, D. (1972). Germinal vesicle breakdown in the mouse oocyte. J Cel/ Sci 10: 369-85.

CHOI, T., AOKI, F., MORI, M., YAMASHITA, M., NAGAHAMA, Y. and KOHMOTO K. (1991). Activation of p34cdc2 protein kinase activity in meiotic and mitotic cell cycles in mouse oocytes and embryos. Development 113: 789-95.

CUTHBERTSON, K.S. (1983). Parthenogenetic activation of mouse oocytes in vitro with ethanol and benzyl alcohol. J Exp Zoo/226: 311-4.

CUTHBERTSON, K.S., WHITTINGHAM, D.G. and COBBOLD, P.H. (1981). Free $\mathrm{Ca} 2+$ increases in exponential phases during mouse oocyte activation. Nature 294: 754-7. 
DE LA FUENTE, R. and EPPIG, J.J. (2001). Transcriptional activity of the mouse oocyte genome: companion granulosa cells modulate transcription and chromatin remodeling. Dev Bio/229: 224-36.

DE LA FUENTE, R., VIVEIROS, M.M., BURNS, K.H., ADASHI, E.Y., MATZUK, M.M. and EPPIG, J.J. (2004). Major chromatin remodeling in the germinal vesicle (GV) of mammalian oocytes is dispensable for global transcriptional silencing but required for centromeric heterochromatin function. Dev Bio/275: 447-58.

DEBEY, P., RENARD, J.P., COPPEY-MOISAN, M., MONNOT, I. and GEZE, M. (1989). Dynamics of chromatin changes in live one-cell mouse embryos: a continuous follow-up by fluorescence microscopy. Exp Cell Res 183: 413-33.

DEBEY, P., SZÖLLÖSI, M.S., SZÖLLÖSI, D., VAUTIER, D., GIROUSSE, A. and BESOMBES, D. (1993). Competent mouse oocytes isolated from antral follicles exhibit different chromatin organization and follow different maturation dynamics. Mol Reprod Dev 36: 59-74.

DIMITROVA, D.S. and BEREZNEY, R. (2002). The spatio-temporal organization of DNA replication sites is identical in primary, immortalized and transformed mammalian cells. J Cell Sci 115: 4037-51.

DIMITROVA, D.S., PROKHOROVA, T.A., BLOW, J.J., TODOROV, I.T. and GILBERT, D.M. (2002). Mammalian nuclei become licensed for DNA replication during late telophase. J Cell Sci115: 51-9.

DIMITROVA, D.S., TODOROV, I.T., MELENDY, T. and GILBERT, D.M. (1999). Mcm2, but not RPA, is a component of the mammalian early G1-phase prereplication complex. J Cel/ Bio/146: 709-22.

EWARD, K.L., OBERMANN, E.C., SHREERAM, S., LODDO, M., FANSHAWE, T., WILLIAMS, C., JUNG, H.I., PREVOST, A.T., BLOW, J.J., STOEBER, K. et al. (2004). DNA replication licensing in somatic and germ cells. J Cell Sci117: 5875-86.

FORSBURG, S.L. (2004). Eukaryotic MCM proteins: beyond replication initiation. Microbiol Mol Biol Rev 68: 109-31.

FULTON, B.P. and WHITTINGHAM, D.G. (1978). Activation of mammalian oocytes by intracellular injection of calcium. Nature 273: 149-51.

KIMURA, H., NOZAKI, N. and SUGIMOTO, K. (1994). DNA polymerase alpha associated protein $\mathrm{P} 1$, a murine homolog of yeast $\mathrm{MCM} 3$, changes its intranuclear distribution during the DNA synthetic period. EMBO J13: 4311-20.

LAEMMLI, U.K. (1970). Cleavage of structural proteins during the assembly of the head of bacteriophage T4. Nature 227: 680-5.

LEI, M. and TYE, B.K. (2001). Initiating DNA synthesis: from recruiting to activating the MCM complex. J Cell Sci114: 1447-54.

LEMAîTRE, J.M., BOCQUET, S. and MECHALI, M. (2002). Competence to replicate in the unfertilized egg is conferred by Cdc6 during meiotic maturation. Nature 419: 718-22.

LEMAÎTRE, J.M., BOCQUET, S., TERRET, M.E., NAMDAR, M., AIT-AHMED, O., KEARSEY, S., VERLHAC, M.H. and MECHALI, M. (2004). The regulation of competence to replicate in meiosis by $\mathrm{Cdc} 6$ is conserved during evolution. Mo/ Reprod Dev 69: 94-100.

LÉNÁRT, P. and ELLENBERG, J. (2003). Nuclear envelope dynamics in oocytes: from germinal vesicle breakdown to mitosis. Curr Opin Cell Biol15: 88-95.

LÉNÁRT, P., RABUT, G., DAIGLE, N., HAND, A.R., TERASAKI, M. and ELLENBERG, J. (2003). Nuclear envelope breakdown in starfish oocytes proceeds by partial NPC disassembly followed by a rapidly spreading fenestration of nuclear membranes. J Cel/ Bio/160: 1055-68.

LIMA-DE-FARIA, A. and BORUM, K. (1962). The period of DNA synthesis prior to meiosis in the mouse. $J$ Cel/ Bio/14: 381-8.

MADINE, M.A., SWIETLIK, M., PELIZON, C., ROMANOWSKI, P., MILLS, A.D. and LASKEY, R.A. (2000). The roles of the MCM, ORC and Cdc6 proteins in determining the replication competence of chromatin in quiescent cells. JStruct Biol129: 198-210.

MANGIA, F. and EPSTEIN, C.J. (1975). Biochemical studies of growing mouse oocytes: preparation of oocytes and analysis of glucose-6-phosphate dehydrogenase and lactate dehydrogenase activities. Dev Bio/45: 211-20.

MASUDA, T., MIMURA, S. and TAKISAWA, H. (2003). CDK- and Cdc45-dependent priming of the MCM complex on chromatin during S-phase in Xenopus egg extracts: possible activation of MCM helicase by association with Cdc45. Genes Cel/s 8: 145-61.

NISHITANI, H. and LYGEROU, Z. (2002). Control of DNA replication licensing in a cell cycle. Genes Cells 7: 523-34.

NURSE, P. (1997). Regulation of the eukaryotic cell cycle. Eur J Cancer33: 1002-

PASION, S.G. and FORSBURG, S.L. (1999). Nuclear localization of Schizosaccharomyces pombe Mcm2/Cdc19p requires MCM complex assembly. Mol Biol Cel/ 10: 4043-57

PETERS, H., LEVY, E. and CRONE, M. (1962). Deoxyribonucleic acid synthesis in oocytes of mouse embryos. Nature 195: 915-6.

PRASANTH, S.G., MENDEZ, J., PRASANTH, K.V. and STILLMAN, B. (2004). Dynamics of pre-replication complex proteins during the cell division cycle. Philos Trans $R$ Soc Lond B Biol Sci359: 7-16.

SUN, W., HOLA, M., PEDLEY, K., TADA, S., BLOW, J.J., TODOROV, I.T., KEARSEY, S.E. and BROOKS, R.F. (2000). The replication capacity of intact mammalian nuclei in Xenopus egg extracts declines with quiescence, but the residual DNA synthesis is independent of Xenopus MCM proteins. JCe//SCi113 (Pt 4): 683-95

TODOROV, I.T., ATTARAN, A. and KEARSEY, S.E. (1995). BM28, a human member of the MCM2-3-5 family, is displaced from chromatin during DNA replication. J Cel/ Biol129: 1433-45.

WHITMIRE, E., KHAN, B. and COUÉ, M. (2002). Cdc6 synthesis regulates replication competence in Xenopus oocytes. Nature 419: 722-5.

YANKULOV, K., TODOROV, I., ROMANOWSKI, P., LICATALOSI, D., CILLI, K., MCCRACKEN, S., LASKEY, R. and BENTLEY, D.L. (1999). MCM proteins are associated with RNA polymerase II holoenzyme. Mo/ Cell Bio/19: 6154-63.

ZUCCOTTI, M., PICCINELLI, A., GIORGI ROSSI, P., GARAGNA, S. and REDI, C.A. (1995). Chromatin organization during mouse oocyte growth. Mol Reprod Dev 41: 479-85

Received: 8th November 2006 Reviewed by Referees: 15th December 2006 Modified by Authors and Accepted for Publication: 23rd March 2007 Published Online: 4th May 2007 


\section{SUPPLEMENTARY MATERIAL}

\section{Control of specificity of primary antibodies}

\section{Western blotting}

The specificity of primary antibodies was confirmed on the Western blots on protein lysats prepared by homogenization of the ovaries obtained from sexually immature (13 days old) or sexually mature ( 2 months old) females in ELB lyses buffer $(0.1 \%$ $\mathrm{NP}-40,160 \mathrm{mM} \mathrm{NaCl}, 50 \mathrm{mM}$ HEPES, $50 \mathrm{mM}$ EDTA). Four ovaries from immature females and two ovaries from mature female were used for preparing the protein lysats. These lysats contained the $\mathrm{Mcm}$ proteins present in oocytes and in the ovarian somatic cells. Additionally, the specificity of anti-Mcm2 antibody was analyzed on Western blot prepared from ovulated oocytes. Two hundred and fifty oocytes were washed in $\mathrm{PBS}_{\mathrm{A}}$, collected in loading buffer (Laemmli, 1970) and boiled for $10 \mathrm{~min}$. Three micrograms of the proteins were separated by $8 \%$ SDS-PAGE

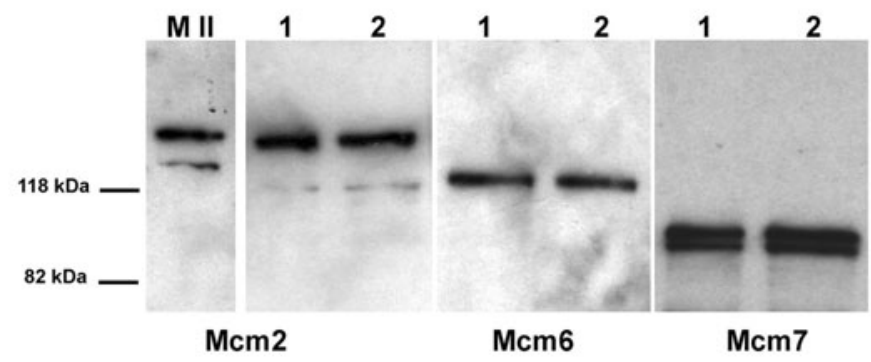

Fig. S1 (Above). Western blot analysis of $\mathbf{M c m}$ proteins in protein lysats. Protein extracts obtained from 250 ovulated oocytes (MII), four immature ovaries (10 dpp), lane (1) and two ovaries from mature females (2) were separated by SDS-PAGE and examined by immunoblotting with anti-Mcm2, -Mcm6 and -Mcm7 antibodies. Hypophosphorylated (insoluble) and hyperphosphorylated (soluble) forms of Mcm2 and Mcm7 are represented by two bands. The picture is the combination of four immunoblots.

Fig. S2 (Right). Immunodetection of soluble and insoluble Mcm2, -6 and -7 in non-synchronised culture of $\mathbf{C 2 C 1 2}$ cells. Chromatin is colored in red; $\mathrm{Mcm}$ proteins are colored in green. The signal of soluble Mcm2 (A$\left.\mathbf{A}^{\prime \prime}\right), \mathbf{M c m 6}$ (C-C") and $\mathrm{Mcm}$ ( (E-E") proteins is visible in the nuclei of nonextracted cells in interphase and in the cytoplasm of non-extracted cells in mitosis. See arrows in $\left(\mathbf{A}^{\prime}, \mathbf{C}^{\prime}\right)$. Interphase nuclei differ in the intensity of staining; see arrowheads in $\left(\mathbf{A}^{\prime}, \mathbf{C}^{\prime}\right)$. In some extracted cells, insoluble

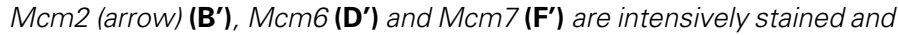
form numerous patches. In the other cells signal of insoluble form of

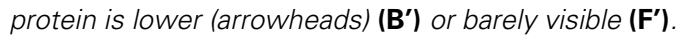

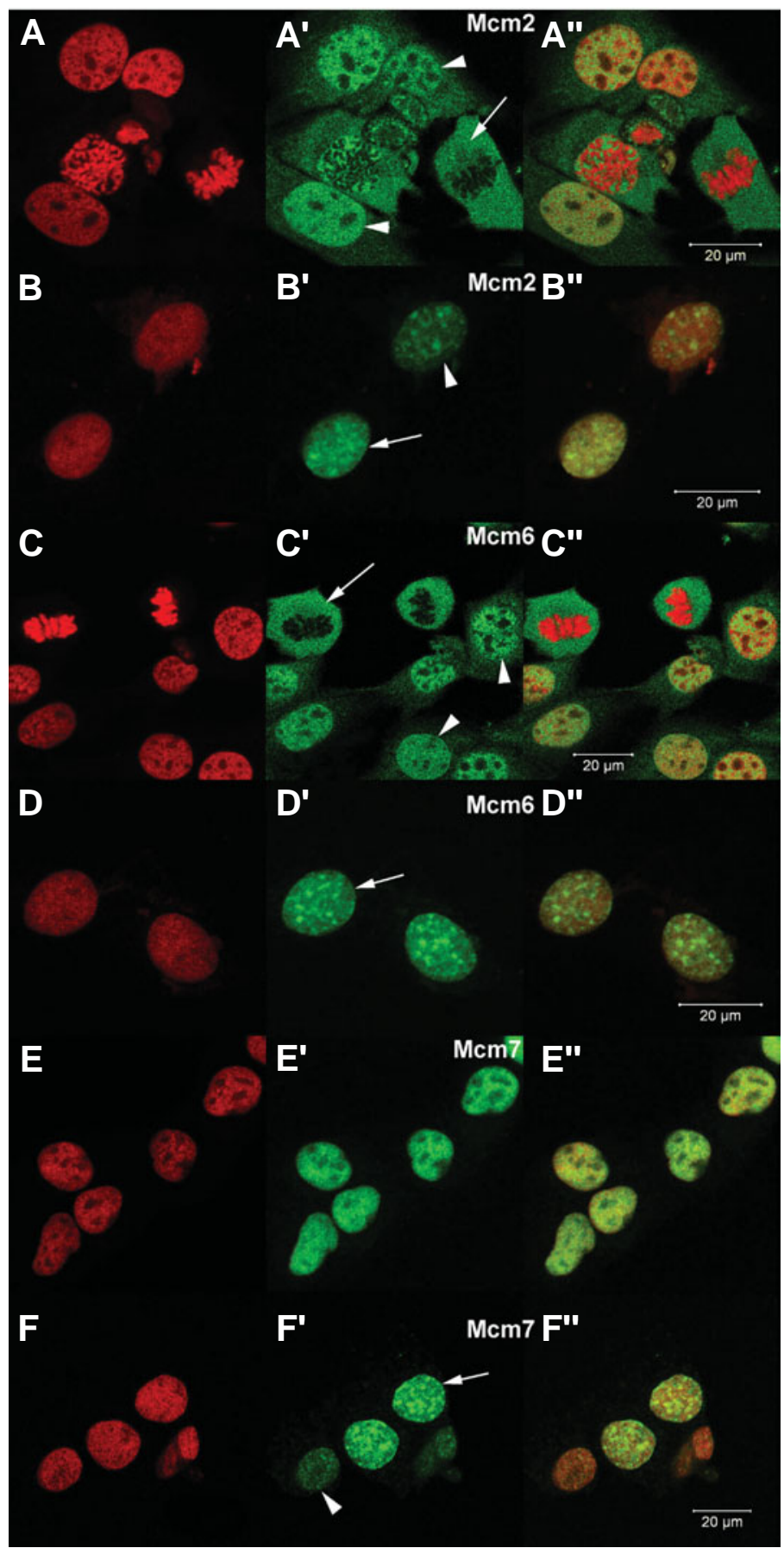




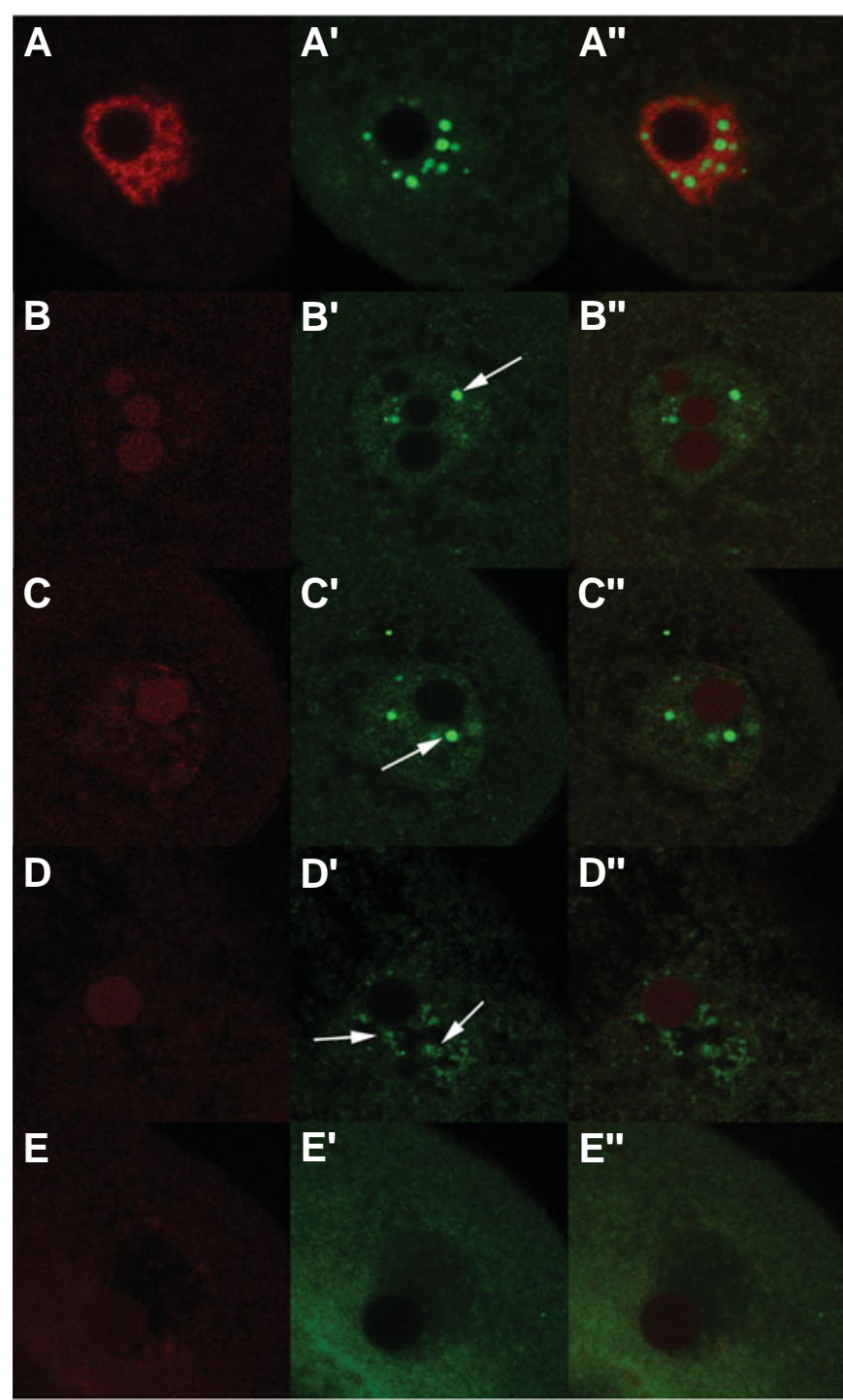

Fig. S3. Immunodetection of Mcm2 in fully-grown oocytes treated with DNase I. Chromatin is colored in red, while the $\mathrm{Mcm} 2$ protein is colored in green. (A-A") Control NSN oocyte extracted for $30 \mathrm{~min}$. in $37^{\circ} \mathrm{C}$. (B-B", C-C") NSN oocytes digested with DNase I for 10 min. Single granules of insoluble Mcm2 protein, see arrows in $\left(\mathbf{B}^{\prime}, \mathbf{C}^{\prime}\right)$, and remnants of chromatin are visible in the nucleus. (D-D") SN oocyte digested with DNase I for 10 min. Insoluble Mcm2 protein forms irregular patches dispersed in the nucleus; see arrows in ('D'). (E-E") SN oocyte after $30 \mathrm{~min}$. of treatment with DNase I. The insoluble form of Mcm2 has disappeared from the nucleus.

and transferred to nitrocellulose membranes (Hybond-P, Amersham Bioscience). Following transfer and blocking for $2 \mathrm{~h}$ in skim milk in PBS, blot was incubated overnight at $4^{\circ} \mathrm{C}$ with one of the primary antibodies: anti-Mcm2 (N-19, sc-9839), anti-Mcm6 (C-20, sc-9843) or anti-Mcm7 (sc-9966) (Santa Cruz Biotechnology Inc., USA; dilution $1: 1000$ in 5\% BSA in PBS/Tween), washed three times in PBS/ $0,5 \%$ Tween (10 $\mathrm{min}$. each) incubated with secondary antibodies: rabbit anti-goat IgG $(\mathrm{H}+\mathrm{L})$, Bio-Rad, USA (dilution 1:10000 in 5\% BSA in PBS/Tween) or goat anti-mouse IgG $(H+L)$, Santa Cruz (dilution 1:7500 in 5\% BSA in PBS/Tween), conjugated with horseradish peroxidase (HRP). Blots were washed 3 times in PBS/Tween and then processed using the ECL detection system (SuperSignal ${ }^{\circledR}$, Pierce, USA). (Immunoblots are presented on Fig. S1).

\section{Immunodetection of Mcm2, -6 and -7 in somatic cells}

Specificity of the primary antibodies has been verified by immunodetection of $\mathrm{Mcm}$ proteins in mouse somatic cells growing in culture. C2C12 cells (mouse myoblasts) purchased from European Collection of Cell Cultures were grown in Dulbecco's modified Eagle's medium (DMEM; Invitrogen, Eugene, USA) supplemented with 10\% FBS and antibiotics (Invitrogen, Eugene, USA) in the presence of 5\% $\mathrm{CO}_{2}$ under humidified atmosphere. Cells were seeded on $22 \mathrm{~mm} \mathrm{1 \%}$ gelatin-coated glass cover slides placed in each well of a 6 -well plate $\left(3 \times 10^{4}\right.$ cells $\left./ 35 \mathrm{~mm}\right)$. After $48 \mathrm{~h}$ of culture cells were used for extraction procedure and/or immunostaining. The extraction was performed according to the method described by Todorov et al. (1995). Extracted and non-extracted cells were fixed in 4\% PFA in PBS $_{A}$ for 20 min. and blocked in $2 \%$ BSA in $\mathrm{PBS}_{\mathrm{A}}$ for at least $30 \mathrm{~min}$. Obtained

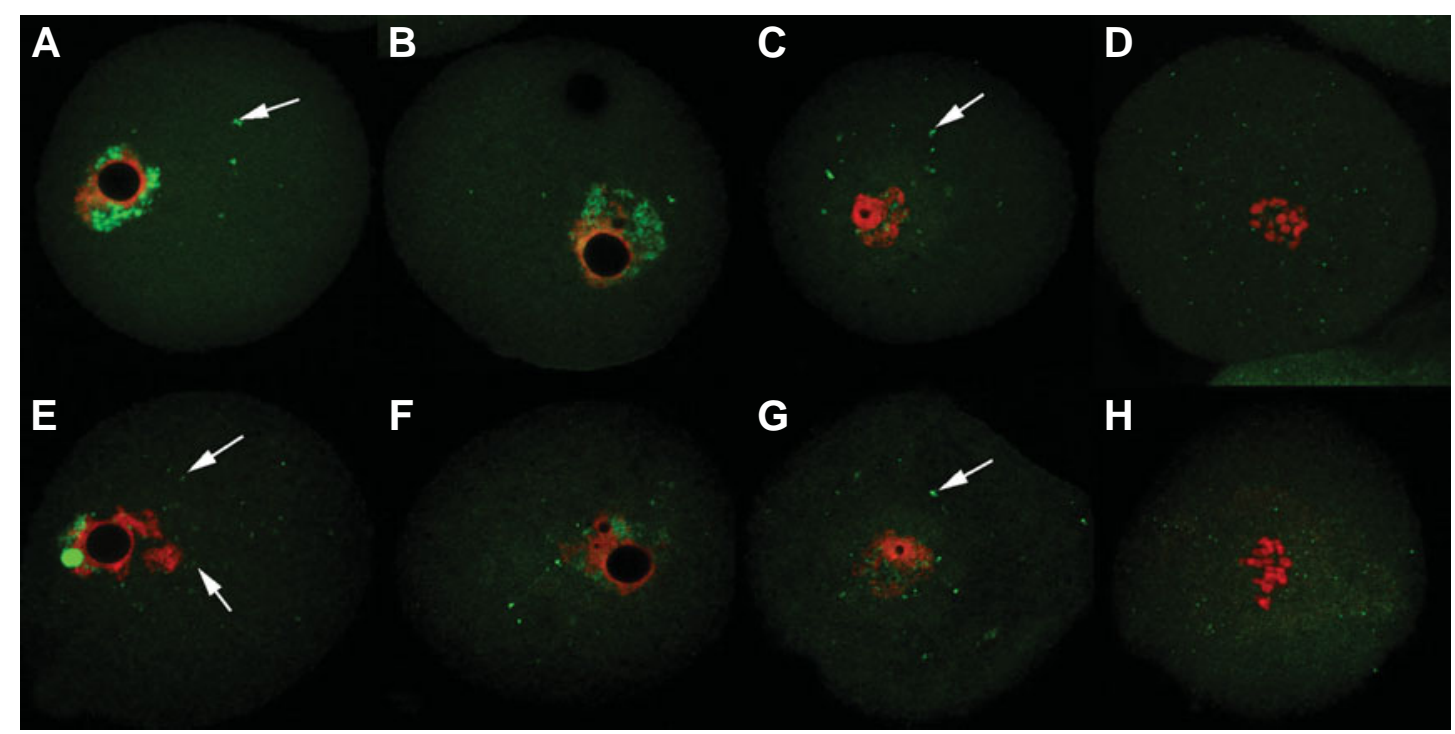

Fig. S4. Distribution of the insoluble form of $\mathrm{Mcm} 2$ in oocytes maturing in the presence of cycloheximide (CHX). Chromatin is colored in red, the Mcm2 protein is colored in green. (A-D) Oocytes cultured in the presence of CHX. (E-H) Control oocytes. In GV-intact oocytes treated with $\mathrm{CHX}, \mathrm{Mcm} 2$ formed many small granules assembled near the nucleolus (A). With prolonged culture (2 h), $\mathrm{Mcm} 2$ signal became more diffuse (B). Cytoplasmic dots of $\mathrm{Mcm} 2$ visible in GV-intact and maturing $\mathrm{CHX}$-treated oocytes (A-D) and in control oocytes (E-H). (C,G) GVBD; (D,H) prometaphase I. 


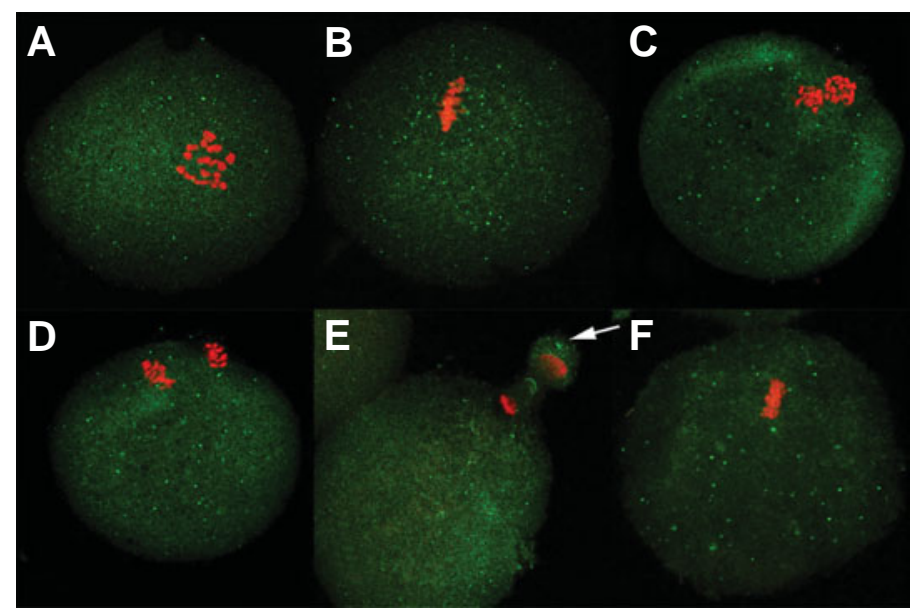

Fig. S5. Distribution of the insoluble form of Mcm2 in oocytes maturing in vivo. Chromatin is colored in red, while the Mcm2 protein is colored in green. (A) $6 \mathrm{~h}$ after $h C G$. (B-E) 8-9 $h$ after $h C G$. (B) MI. (C,D) Anaphase I. (E) Telophase I (arrow indicates the $1^{\text {st }}$ polar body). (F) $12 \mathrm{~h}$ after hCG (metaphase II). In all stages Mcm2-positive dots are scattered randomly in the cytoplasm.

results showed that in non-synchronized cell culture the soluble form of Mcm2, -6 and -7 was present in the nuclei of interphase cells and in the cytoplasm of mitotic cells (Fig. 2S A',C'; arrows). The intensity of staining of some nuclei differed slightly (Fig. S2 A', C', arrowheads). This differences were much better visible in cells submitted to extraction procedure, in which only the insoluble form of analyzed proteins was detected (Fig. S2 B', D',F'). In some cells the intensity of staining in the nuclei was similar to observed in non-extracted cells and additionally irregular patches of the protein were visible (Fig. S2 B',D',F'; arrows). In the other cells the number of patches and the staining of the background in the nucleus was lower (Fig. S2B'; arrowhead) or was barely visible (Fig. S2F'; arrowhead). Observed differences reflect changes in the association of the $\mathrm{Mcm}$ proteins with the chromatin taking place during the cell cycle as it was described earlier (Todorov, 1995; Dimitrova and Berezney, 2002). Results presented above confirmed the specificity of primary antibodies used in the present work.

\section{Protein synthesis is not required for the reappearance of cytoplasmic deposits of insoluble Mcm2 protein}

To verify whether the reappearance of Mcm2-positive deposits in maturing oocytes depends on the protein synthesis de novo, oocytes classified as SN type were cultured in the continuous presence of protein synthesis inhibitor, cycloheximide $(\mathrm{CHX}, 10$ $\mathrm{mg} / \mathrm{ml}$ ). GV-intact oocytes were cultured for 2 or $6 \mathrm{~h}$ in M2+dbcAMP supplemented with $\mathrm{CHX}$. Then, the dbcAMP was washed out to induce meiotic maturation and the oocytes were cultured in M2 with $\mathrm{CHX}$ for up to $6 \mathrm{~h}$. Oocytes not treated with $\mathrm{CHX}$ and cultured in standard conditions served as a control group. In GV-intact oocytes cultured in the presence of $\mathrm{CHX}$, large aggregates of Mcm2 were no more observed. Instead of them, numerous small granules of the protein situated near the nucleolus and few Mcm2positive dots in the cytoplasm were observed (Fig. S4 A,B). In control, GV-intact oocytes, cultured for the same period of time in $\mathrm{CHX}$-free medium, large aggregates of $\mathrm{Mcm} 2$ were also rarely visible. In most cases only 1 or 2 granules of the protein, larger than observed in $\mathrm{CHX}$-treated oocytes and regular in shape were present in the nucleus. Sometimes few Mcm2-positive dots were observed in the cytoplasm (Fig. S4E, arrows). After removing of dbcAMP, when oocytes underwent GVBD, in both control and CHX-treated oocytes, the Mcm2-positive deposits appeared in the cytoplasm. They disappeared about $20-30 \mathrm{~min}$. later and reappeared $3-4 \mathrm{~h}$ after GVBD (Fig. S4 C,D - CHX treated and $\mathrm{G}, \mathrm{H}$ - control oocytes). These results show that appearance of cytoplasmic Mcm2-positive dots in maturing oocytes does not depend of ongoing protein synthesis.

\section{Related, previously published Int. J. Dev. Biol. articles}

See our recent Special Issue on Mammalian Reproduction and Development edited by Brigid Hogan at: http://www.ijdb.ehu.es/web/contents.php?vol=45\&issue=3

See our forthcoming Special Issue on Developmental Biology in Poland edited by Malgorzata Kloc, Marek Maleszewski and Andrzej K. Tarkowski at: http://www.intjdevbiol.com

Dynamic distribution of the replacement histone variant $\mathrm{H} 3.3$ in the mouse oocyte and preimplantation embryos Maria-Elena Torres-Padilla, Andrew J. Bannister, Paul J. Hurd, Tony Kouzarides and Magdalena Zernicka-Goetz Int. J. Dev. Biol. (2006) 50: 455-461

Delivery of germinal granules and localized RNAs via the messenger transport organizer pathway to the vegetal cortex of Xenopus oocytes occurs through directional expansion of the mitochondrial cloud Katarzyna Wilk, Szczepan Bilinski, Matthew T. Dougherty and Malgorzata Kloc Int. J. Dev. Biol. (2005) 49: 17-21 


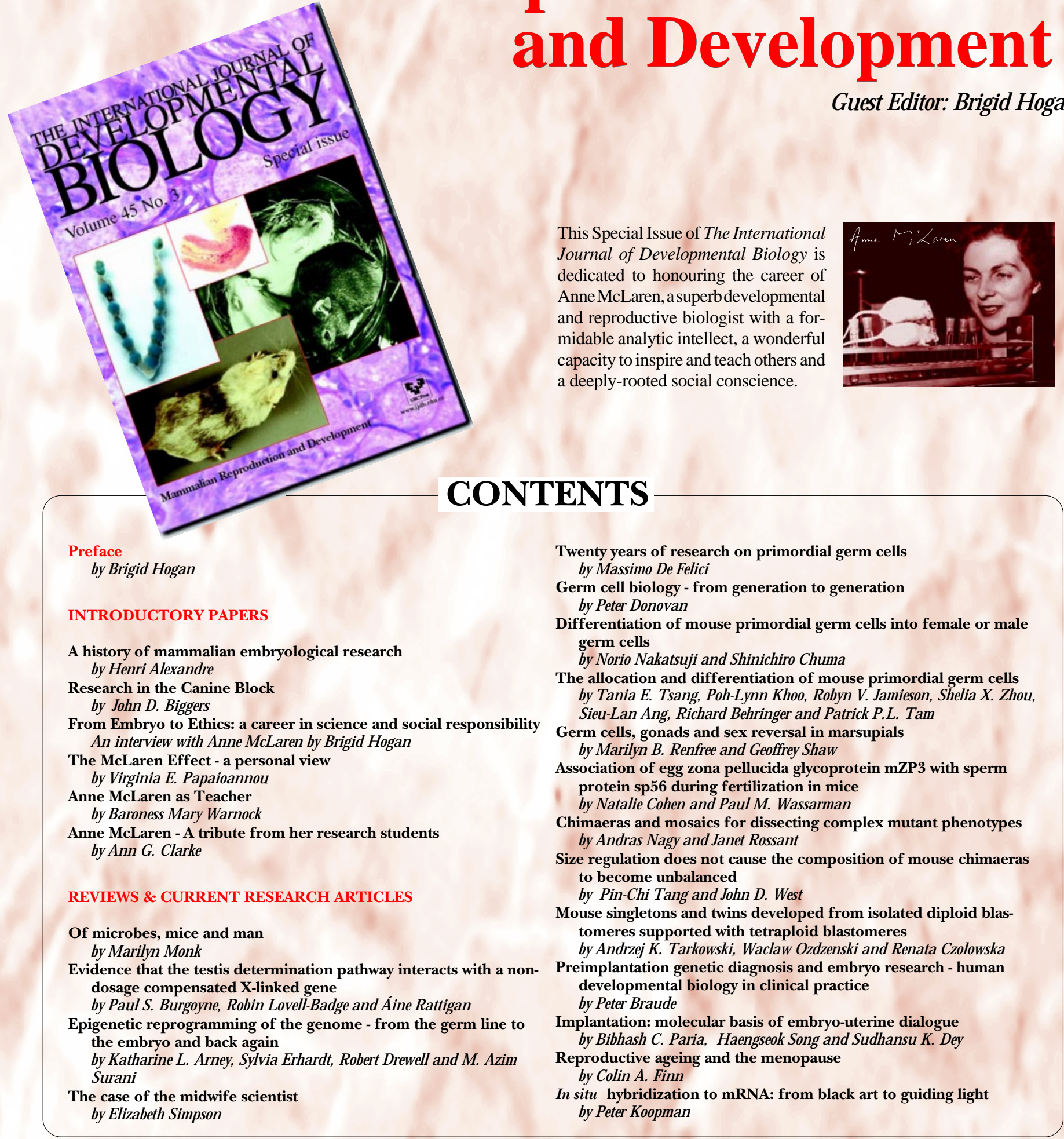

\section{ORDER FORM}

I would like to order ___ cop(y/ies) of the Int. J. Dev. Biol. Special Issue “Mammalian Reproduction and Development” (Vol. 45, № 3) at US\$ 90 or Euro $€ 70$ per copy (including post and packaging). Total to be charged: US\$ / Euro $€$ (please specify currency)

\section{ORDER BY}

$\checkmark$ Web: http://www.intjdevbiol.com

$\checkmark$ E-mail: ijdb@ehu.es (include the information indicated above)

$\checkmark$ FAX: +34-94-601-3266

$\checkmark$ POST: to the address shown beside
The International Journal of Developmental Biology

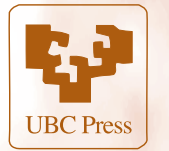

UBC Press - Faculty of Medicine

University of the Basque Country, E-48940 Leioa, Vizcaya,

SPAIN 